DRAFT VERSION

THIS PAPER WAS PRESENTED AT ASA MEETING 2019, NEW YORK

\title{
Cultural capital in China? \\ Television tastes and cultural distinction among college students in Beijing
}

\author{
Yang GAO, Furman University \\ yang.gao@furman.edu \\ Giselinde KUIPERS, Catholic University Leuven \\ giselinde.kuipers@kuleuven.be
}

\begin{abstract}
:
Can television taste function as cultural capital in contemporary China? This paper investigates, for the first time, how Chinese engage with global pop culture to mark their positions in China's swiftly changing social and cultural hierarchies. Using multiple correspondence analysis (MCA) of a survey ( $\mathrm{n}=422)$ and 48 interviews with students at an elite Beijing university, we identify three distinct taste dimensions: not-knowers versus dislikers; TV lovers versus avoiders; and Western and Eastern TV taste. We identify dimensions 1 and 3 as cultural capital dimensions: respondents on the "high end" draw taste-based social boundaries vis-à-vis those on the low end, who in turn accept the hierarchies implied in these tastes. The two dimensions differ in the criteria used to make aesthetic distinctions, the type of cultural knowledge they rely on, and in the strength of their boundarydrawing. We conclude that the "Western" taste is more exclusive than the "dislike" taste. The first is mainly based on aesthetic criteria (complexity, authenticity), whereas the second combines aesthetic (complexity, depth) and cosmopolitan (language skills, international experience) distinctions. While the liking of both dimensions is related to parental cultural capital (education, occupation, urbanity), the "Western" taste also correlates with parental economic capital and international experience. This "discovery" of cultural capital in China has implications for our understanding of cultural and cosmopolitan capital, of the global diffusion of cultural goods and the aesthetic and status systems implied in these goods, and for our understanding of culture and stratification in China.
\end{abstract}




\section{Introduction: a "chain of disdain" in Chinese television tastes?}

Economic reforms and opening-up have made China an increasingly differentiated society with a strong and growing middle class. Meanwhile, drastic social change and globalization have heralded a new era of cultural abundance in Chinese society. Chinese consumers today can choose from popular culture produced around the world: China, the US, but also Europe, Japan and Korea. Given the close connection between social stratification and cultural distinction (Bourdieu 1984), we expect that such new opportunities for cultural consumption allows for the emergence of new forms of cultural capital. This paper investigates, for the first time, how Chinese youth engage with global pop culture to mark their positions in contemporary China's swiftly changing social and cultural hierarchy. Based on statistical analysis of 422 surveys and 48 in-depth interviewees with selected survey takers, this article explores this issue by examining the tastes for different television drama among college students in Beijing.

Television has long been considered an inferior cultural form of entertainment rather than art, mainly because it was seen as commercial and mass-oriented (Adorno \& Horkheimer 1979 [1944]; Bourdieu 1984; Postman 1985). However, like popular music, television has increasingly become a domain for distinctive cultural consumption (Kuipers 2006; Warde et al. 2009). The recent diversification of the TV landscape, particularly that of the US and the UK-the world's dominant TV exporters (Kuipers 2011; Straubhaar 2007) - has marked TV's artistic ascendance. In the US, for example, scholars and critics have taken note of the arrival of “quality TV” (McCabe \& Akass 2007), “complex TV” (Mittell 2015), or TV's “Third Golden Age” (Martin 2013), where series with complex and innovative storytelling have scored remarkable creative and economic success in the last two decades. Thus, like in popular music, we now see stratification within television fiction, distinguishing "lowbrow" popular drama from more prestigious quality fare.

In addition to ground-breaking storytelling and genre innovation, another component of TV's aesthetic upward mobility is its "intellectualization." Similar to the intellectualization of film in the US over the twentieth century (Baumann 2007), a combination of technological, industrial, and cultural changes has allowed television to begin garnering the kind of respect paid to such acclaimed cultural objects as the fine arts, books, and movies (Lotz 2014; Bianculli 2016). The proliferation and diversification of television makes TV consumption a fertile field in which to study the relations between viewers' cultural tastes and their social positions (Kuipers 2006; Lizardo \& Skiles 2009; McCoy \& Scarborough 2014; Warde et al. 2009).

Contrary to the long-lasting and still common Western perception of television as the lowest of media, in China television was a symbol of modernity when it entered family life in the 1980s (Lull 1991). Since the consumer revolution hit stride around the mid-1990s, both the overall quality and variety of domestically produced Chinese television have been growing leaps and bounds (Xu 2009; Zhu \& Berry 2009). Meanwhile, technological advances and cultural globalization have worked in tandem to further expand the Chinese audience's viewing options. Over the past decades, Chinese audiences were presented with a growing range of television programs from around the world: programs from the US and (to a lesser extent) the UK, but also 
from various Asian countries. Japanese television drama was imported into China as early as the late 1970s (Cui 2010). In recent decades, the so-called "Korean wave" led to the proliferation of Korean popular culture across East Asia, garnering a strong following in China (Chua \& Iwabuchi 2008; Ryoo 2009). This "wave" includes television programs, especially a special kind of long-running rather dramatic serial (often described as "soap"), popular music (so-called K-pop), and a specific celebrity culture.

As in other countries, television in China has become more differentiated in origin, style, perceived quality and intended audience. In addition, it has proliferated across platforms. Thus, television offers increasing opportunities for the emergence of "taste cultures" and thus for distinctive practices. As different types of audiences, purportedly of different backgrounds, cluster around various shows-both in terms of genre and country of origin — a taste hierarchy seems to be emerging, with a prominent global twist. Specifically, a widely recognized bishi lian (literally, a "chain of disdain") epitomizes the taste hierarchy among viewers who prefer shows from different countries (China Daily 2015). Although the exact ranking varies depending on whom you ask, English language programming tends to reside at the top of the chain, whereas mainland Chinese TV or Korean TV tends to be positioned at the bottom.

The expression of a "chain of disdain" was popularized, and to some extent codified, by the lead article in the April, 2012 issue of City Weekly (a magazine owned by China's top daily newspaper Southern Metropolis Daily). The article enumerated different kinds of "chains of disdain" in various kinds of cultural goods, including clothing, music, magazines, video games, movies, and TV shows. On top of the "chain" in the cover image of that issue of City Weekly are the logo of BBC and the image of Sheldon Cooper, a fictional character in CBS's hit comedy The Big Bang Theory.

While tongue-in-cheek, the "chain of disdain" in TV consumption raises important questions about emerging taste hierarchies in a quickly differentiating China. As Chinese audiences, especially the young and technologically savvy, have ever easier access to growing viewing options, how do they navigate the cultural abundance with which they are confronted? Who likes what shows, and what cultural logics inform their tastes? How are viewers' attraction or aversion to different shows related to their social positions? Are there distinct discourses regarding TV shows from particular countries? And what sorts of criteria are deployed in accounting for various tastes and preferences? In other words: is there cultural capital in Chinese television consumption? And if so, how does it work?

This article presents what is, to the best of our knowledge, the first study of social background and cultural capital in China. Inspired by the popular discourse on "the chain of disdain", we focus on the television taste of Chinese students. Taking our cue from Bourdieu's classical study, we use a Multiple Correspondence Analysis (MCA) of survey data, and in-depth interviews to investigate first, if there are patterns of cultural preference and aversion that can be interpreted as cultural capital; and second, if we find evidence of the particular patterns of cultural distinction related to the regional origin of TV programs, as implied in this "chain of disdain". 


\section{Taste, hierarchy and television: Exploring cultural capital in China}

Taste-knowledge of and preference for particular cultural goods - is a key concept in the sociology of culture. In Distinction: A Social Critique of the Judgement of Taste, Bourdieu (1984) connects people's seemingly innocuous cultural tastes with their struggle for social status. Mapping aesthetic preferences in 1960s France against class relations, Bourdieu demonstrates the homologies between hierarchies of cultural tastes (from the high/legitimate to the low/popular; and from more conventional to more avant-garde) and the relative social and economic positions of people with different tastes. Central to Bourdieu's analysis is the distinction between economic capital or wealth, which is signaled by conspicuous consumption, and cultural capital, which is signaled by good taste. The appreciation of legitimate culture that can only be acquired over time, by education or by long-term immersion in the right social milieu (Bourdieu 1986). Therefore, cultural capital is only recognized by those who are "in the know". This knowingness gives access to privileged social circles and thus (if all goes well) to materials benefits such as higher income. Later scholars also show that, by dividing cultural artifacts and activities into categories, the culturally privileged create and maintain symbolic boundaries between themselves and those who consume "lowbrow" culture (Lamont \& Fournier 1992; Lamont \& Molnár 2002).

The Bourdieusian approach thus emphasizes the social stratifying power of cultural taste: class domination is achieved through economic resources but also command of "legitimate" or elite culture. Key to the class reproduction via cultural taste is the concept of habitus_our habits, skills, knowledge, as well as general dispositions. Habitus powerfully shapes our cultural taste, often without us realizing it. This is because habitus is formed through a complex process of socialization—including family upbringing and formal education —and is so ingrained in us that it becomes our second nature. Thus, growing up in privileged circumstances not only means that one can afford to go to the opera, purchase priceless art, and dine in luxurious restaurants. It means that one is able to "decode" and thus appreciate legitimate culture, and speak eloquently about one's tastes and consumption. To the extent that legitimate taste-knowledge, familiarity, and appreciation of the texts and practices of "legitimate" culture-associates one with higher classes, it is a currency of social distinction. In other words, taste is a form of cultural capital.

Later researchers have furthered the idea that privileged groups establish and maintain distinction not only through gravitating toward certain cultural products but also through consuming those products in particular ways (e.g., Friedman 2011; Holt 1997; Kuipers 2006; McCoy \& Scarborough 2014). In his original work, Bourdieu observes that the appreciation of legitimate culture, in particular European highbrow culture, requires a "disinterested aesthetic disposition" - a certain way of appreciating art in which one puts aside any emotional or moral interest in an art work and instead focuses on its formal characteristics (Bourdieu 1984: 28-42). In other words, it is not just what one enjoys, but how one enjoys that is telling. This insight is especially useful in understanding the emerging "omnivorous" tastes (Peterson \& Kern 1996) in an increasingly fragmentary pop cultural landscape. Specifically, content that is traditionally labeled "lowbrow" (commercial, artistically inferior), such as comedies (Friedman 2011; Kuipers 2006), "bad" television (McCoy \& Scarborough 2014), and salsa 
music (Bachmayer, Wilterdink, \& van Venrooij 2014), can still be used by people of higher social status to distinguish themselves culturally, as long as they demonstrate the legitimate "styles of appreciation" (Friedman 2011; Prieur \& Savage 2013; Jarness 2015), i.e., using appropriate knowledge to engage lowbrow culture in distanced, sophisticated, critical, or otherwise "enlightened" ways.

Bourdieu's arguments about taste, cultural capital, and social distinction were based on research done in the 1960s France, where a particular legitimate culture was more established and class boundaries more rigid. Moreover, the French, and more general European societies have traditionally been marked by a strong opposition between cultural and economic elites. As a consequence, culture became the privileged battlefield for status struggles. Many authors have suggested that this special status of "highbrow" culture is specifically European, and less applicable in North-America (Lamont 1992; Peterson 2005). Studies conducted in the US, have pinpointed a more "loosely bounded culture," where cultural products and practices are less clearly hierarchized, class boundaries are less crystalized, and elite tastes are more omnivorous than snobbish (Bryson 1996; Kuipers 2015; Lamont 1992; Peterson \& Kern 1996; Peterson 2005). Most notably, the omnivorousness thesis, stemming from research on American music taste, maintains that even in Europe, the privileged middle and upper classes no longer refrain from lowbrow culture but rather increasingly graze on both high and low cultures (Peterson \& Kern 1996). The thesis has inspired many studies to explore the nature, extent, and significance of the growing eclecticism in the cultural consumption of elites across Western societies (see Peterson 2005 for a comprehensive review). For the Chinese case, it is quite unclear whether the cultural field functions as arena for status struggle, either in the traditional "highbrow" sense, or in the more recent or Americanized "omnivorous" version.

More things have changed since 1960s France. High cultural capital consumers are not only increasingly oriented towards genres considered popular, but their tastes are have also become more cosmopolitan (Calhoun 2002; Weenink 2011; Igarashi \& Saito 2014). For example, Prieur and Savage (2013) note the growing importance of "cosmopolitan cultural capital" among middle and upper classes in Europe and North America, where the capacity to stand outside one's own national frame is becoming a marker of high status. The association between the national vs international orientation in cultural taste and social class cleavages has also been found in non-Western contexts. For example, studying the elite taste culture in Brazil, Hedegard (2015) finds that Brazilian elites demonstrate a "transnational repertoire" of cultural tastes that includes various Western brands, such as Starbucks and Apple. These popular Western cultural forms are reframed as high-status symbols and incorporated into an elite lifestyle in the Brazilian context. Hedegard's study illustrates how the rarity, relative value, and symbolic meaning of cultural objects vary significantly in different national contexts. In the realm of TV consumption, this means that liking a popular US series, say Friends, might mean different things about a Chinese viewer than an American viewer.

Two important insights can be gleaned from existing research on cultural taste and social distinction, which has been primarily conducted in Western contexts. First, taste, though seemingly natural and innate, is 
closely related to people's socio-economic positions and powerfully shaped by a complex process of socialization through the family and education. Second, taste can be used to demarcate social boundaries, but the meaning and significance carried by particular tastes vary considerably in different social and cultural contexts.

In contrast to the West, a socio-economic class system did not exist in China until recently (Li 2010). Until the early $20^{\text {th }}$ century, the Chinese empire (like most of Europe) was an estate society with a largely hereditary stratification system. Such societies with limited mobility require less active policing of social hierarchies than class societies. In the earlier years of the People's Republic, social stratification was based primarily on the family's political classification. Beginning in the 1980s, however, market-oriented economic reforms have given rise to a more class-based social hierarchy resembling that of the West, one that is based on education, income, job status, and consumption (Anagnost 2008; Bian 2002; Fewsmith 2007; Li 2010).

Because of this unique trajectory of modern China's social stratification, the rising Chinese middle class, unlike its counterparts in the West, does not have an established bourgeoisie to emulate. It also lacks access to various forms of status symbols Western elites employ in accumulating cultural capital, such as charity, arts patronage or "old money" networks (Osburg 2013). Additionally, Chinese social differentiation is unfolding under deepening globalization. All these characteristics give status struggles in contemporary China a particular dynamic that is distinct from the European and the North-American patterns. On the one hand, people strive to acquire symbols of wealth to mark their distinction: this is the typical logic of "economic capital" or conspicuous consumption (Davis 2000; Osburg 2013). On the other hand, the symbolic dimension of consumption is ever more prominent. For example, studying the cultural symbolism of Western fast-food restaurants in the 1990s China, Yan (2013) finds that many Chinese chose to dine in KFC and McDonald's not because they enjoyed the food, but because they relished sitting by the window to watch passers-by with a sense of sophistication and superiority. To these people, Western fast food was associated with modernity, and it was "good taste" to be modern. Similarly, in her study of Chinese high school graduates who went on "educational pilgrimages" to the "developed world"-mainly Japan, Australia, Western Europe, and North America - Fong (2011) notes the significant symbolic value of holding a foreign degree, even "developed world citizenship," in these youths' striving for upward social mobility once they return. This suggests that cultural distinction in the Chinese context is intricately connected with foreign, mostly Western tastes and "cosmopolitan capital".

However, these scattered studies of distinctive consumption in China, do not show the deployment of cultural taste as a form of exclusive cultural knowledge that is only accessible to some. Going to KFC—and sitting in the window to be seen — and travelling abroad are forms of cultural consumption that are readable to many. Moreover, they involve money as well as good taste. Thus, these studies do not explicitly tackle the question whether contemporary Chinese recognize cultural capital as a specific form of distinction distinct from economic capital: tastes based in cultural knowledge that is acquired over time.

The aforementioned "chain of disdain" suggests that, during China's recent social reclassification, cultural taste in China has emerged as a means of social distinction. Like tastes in music or art in Europe and the 
US, it suggests that preferences for such mundane things as television shows are not simply different tastes of equal value and worth. Rather, they are differentiated in a hierarchical way, in which the perceived quality of a show is connected to the social status of its perceived audience. Moreover, there seems to be an understanding that things that are more difficult to master are somehow "better" than easily digestible entertainment. Thus, this "chain of disdain" in TV allows us to explore a number of important questions regarding the possible emergence of cultural capital in China.

First, we ask whether there are distinct "taste cultures" (Gans 1974) among Chinese television audiences, using both the results from a survey and interviews. Given our interest in the "chain of disdain", we were particularly looking for "taste cultures" centered around television from specific countries or regions. We replicate the earlier analysis of the second author (Kuipers 2006) of television taste in the Netherlands, identifying pattern of like, dislike and familiarity with a range of television shows from various countries and of various genres. Following Bourdieu, we assume that cultural capital relies on cultural knowledge. Cultural capital is not only a matter of like and dislike. Before like or dislike is possible, cultural capital implies that one must be aware of the existence of specific cultural goods. Therefore, familiarity with cultural goods is centrally important to analyzing cultural capital.

Evaluation - like or dislike - or a specific cultural good is where distinction truly happens. As Bourdieu noted, legitimate culture requires a specific form of knowledge or "eye" to decode and appreciate it, a form of "sophistication" that is learned in school or in interaction with cultured peers or family members. While Bourdieu seems to have implied that the appreciation of popular culture does not really require much in the way of cultural knowledge, later observers have noted that all culture, in fact, requires background knowledge (Friedman 2011; Kuipers 2015). This applies both to cultural fare from one's own country, and imported cultural goods. However, one may assume that some forms of cultural knowledge, notably about local produce, are more easily acquired than knowledge about cultural forms from more remote places. However, it is an open question whether European and American notions of cultural sophistication, which are rooted in the distanced "aesthetic disposition" as described by Bourdieu, work in the Chinese context.

We use interview data to interpret these taste cultures, looking for the discourses and quality criteria people use in evaluating various types of television drama from different countries. What logics do people employ in selecting television programs?? To what extent do these TV discourses and logics lead to hierarchical orderings of shows, groups of shows, or even entire national television industries? Do people draw social boundaries on the basis of TV taste, ths is: do they judge others on the basis of the programs they like to watch? This qualitative analysis allows us to uncover the cultural system (or systems) underlying the various taste cultures, and possible hierarchical orderings underlying judgements of taste. For tastes to function as cultural capital, evaluations of cultural goods must be related to symbolic and social boundaries: evaluations that not only apply to shows but that also spill over the judgments of those who like or dislike these shows. 
In the third and final step in our analysis we look at the relation between the evaluation of television programs and social background. Are certain preferences, taste cultures or repertoires associated with people of specific social backgrounds or social classes? As this is the first study of this kind in China, we find ourselves in uncharted territory here. In the absence of an established measurement of social class, cultural capital or social status, we are looking at a wide selection of social background variables, including parents' education and profession, regional background, income, language skills and international experience. With a rather homogenous sample of college students, and a focus on the popular field of television, it seems unlikely that we will find full homology between social positions and cultural preferences. However, it will allow us to map whether there are particular like or dislikes, forms of knowledge or ignorance, disdain or reverence that are associated with social status and boundary-marking. Thus: we will be able to establish, albeit provisionally, whether there is indeed cultural capital in China, and what it looks like.

\section{Studying taste in China: Methods and Data}

\subsection{Sample and instruments}

The study consisted of a quantitative survey $(\mathrm{n}=422)$ and 48 follow-up in-depth interviews with selected survey takers. A study advertisement with the link to the online survey was sent to 1,800 students randomly sampled in a prestigious national university in Beijing. In addition to gathering respondents' basic demographic information, the survey asked them to indicate their knowledge of and preferences for Chinese and international television shows of various genres.

422 students filled out the survey, a response rate of 23.4 per cent. Approximately a third of the respondents are male, and two thirds are female. The sample contains students from places of different levels of urbanization: about ten per cent of the respondents are from China's four first-tier metropolises (Beijing, Shanghai, Guangzhou, Shenzhen), another ten per cent are from rural areas, and the rest are fairly evenly distributed across different levels of cities and their suburbs. Moreover, student represent a rather wide range of social backgrounds in terms of parental profession, education, and political background (and important variable in China) as well as international experience (e.g. Travel experience, foreign language skills). Other than that, the sample is quite homogeneous in terms of age, income and profession. Moreover, since all informants attend the same selective university, they are similar in terms of academic performance and, one may assume, all have good professional prospects. From the survey takers who expressed interest in participating in a one-on-one in-depth interview, 48 respondents were selected for the interviews. The key criterion of selection was to produce a sample with enough variation in respondents' social origin, particularly regarding their cultural capital resources (indicated by parental education level). 21 of the 48 interviewees are male, and 27 are female.

We gauged respondents' TV tastes both categorically and with more granularity. For the former, we asked respondents to rank TV shows from six different countries or places based on their general preferences. 
These six places are: the US, the UK, mainland China, Hong Kong, South Korea (in this paper, we follow common usage both in China and the West, referring to cultural products from South Korea as "Korean") , and Japan. To make comparisons more feasible and meaningful, we instructed respondents to consider only fictional TV. To further measure tastes for various subgenres of fictional TV, we asked respondents to indicate their knowledge of and preferences for 10 selected shows from each of the six places (60 shows in total), specifically by picking one out of six options (strongly like/ like/ neutral/ dislike/ strongly dislike and "not familiar") that best captured their stance on each selected show.

The priority in selecting the 60 shows was to ensure breadth. In other words, there had to be something in there for everyone. We used two strategies to achieve that goal. First, drawing on the genre categories used by major TV content providers in the US (including networks, cables, and streaming sites) and on the five biggest Chinese streaming sites, we identified ten main genres of fictional TV. Second, to select a particular show for each genre, we used Douban—a Chinese social networking and user reviewing site that is highly reputable and popular among the younger and more educated demographic. We used the site to select TV shows that had been rated by at least 5,000 people at the time. For each of the six countries, two lists of shows were generated, one ranked by "trendiness" and the other by user ratings. Looking at the two lists side by side, we took the show with the highest average rank to represent each of the ten distinct genres. Whenever there was a tie, we chose the show with more raters, as an indicator of greater popularity. The resultant sample is a mix of old and new shows, combining mainstream and various niches. Using US and Chinese TV as an example, Table 1 shows the genre categorization and the selected show for each genre.

Table 1. Genres in the questionnaire, with examples of American and Chinese shows

\begin{tabular}{lcc}
\hline Genre & American show & Chinese show \\
\hline Generic/Romantic Comedy [with Family Appeal] & Friends & My Own Swordsman \\
\hline Satire / Black Comedy & Parks and Recreation & Stories of an Editorial Board \\
\hline Teen drama & The Vampire Diaries & Ode to Joy \\
\hline Sci-fi / Supernatural / Fantasy & Game of Thrones & Journey to the West \\
\hline Professional [Legal or Medical] & The Good Wife & Divorce Lanyers \\
\hline Political drama & House of Cards & For the Sake of the Republic \\
\hline Thriller & Breaking Bad & Lurk \\
\hline Action drama & 24 & Before Dawn \\
\hline Crime / Police Procedural & The Wire & Yu Zui \\
\hline Period drama & Boardwalk Empire & Nirvana in Fire \\
\hline * Parks and Recreation $[\mathrm{NBC}]$ is tied with Veep $[\mathrm{HBO}]$. We chose Parks and Recreation to avoid having 3 HBO shows in a 10-show sample.
\end{tabular}

For the qualitative interviews, we relied on a semi-structured interview protocol that included questions regarding television taste, cultural practices and other leisure time activities, as well as question regarding personal and family background, international experience, and personal ambitions. All interviews were conducted by the first author, face-to-face and in Mandarin Chinese. The interviews were recorded and transcribed in full. 


\subsection{Analysis}

For our data analysis, we replicated the procedures followed by the second author (Kuipers 2006). We did a multiple correspondence analysis (MCA), a method used to find patterns in categorical variables. This method is especially well-suited to studying taste patterns, as these consist of presumably systematic styles of like and dislike of a range of things. MCA was introduced by Bourdieu in Distinction, but has been improved and refined since then. For this analysis, we used the MCA module in R.

In this paper, we focus on the responses to the 60 television shows explained above and the social background variables. An important condition for MCA is a good spread of modalities, that is the "values" of categorical variables (Benzecri 1973; Greenacre and Blasius 1994; Nenanic and Greenacre 2007). Since many of the shows were little known - which is unsurprising in today's fragmented television landscape - analyses of the full sample led to results that were skewed towards the unknown shows. We therefore base our analysis only on the 27 shows known by at least $25 \%$ of our respondents. The other 33 shows are included as so-called supplementary variables: these variables are not used to compute the dimensions, but their score on each of the dimensions can be computed and analyze afterwards (Greenacre \& Blazius 1994). Thus, we can see how they are part of wider television tastes. The same is done for the social background variable. Since we don't want to assume beforehand that social background plays a role in television taste, we include them as supplementary variables. We impute their values afterwards to find out if tastes are related to social background.

The interview findings were analyzed in a two-step procedure, using a theoretically grounded coding scheme. In the first round, all informants were sorted according to their scores on the dimensions that were produced by the MCA. Thus, we used the interview data to interpret the quantitative results. In the second round - which is still in process at the time of writing - we are using a more inductive method to uncover the cultural logics guiding people's evaluations of television programming, and their more general discourses and criteria regarding "good" and "bad" television and its relation to symbolic boundary drawing.

\section{Television taste in China: patterns of familiarity, like and dislike}

\subsection{Tastes in a fragmented TV landscape}

Of the 60 shows in the survey, our informants knew on average 19.5 shows, or 33\%. There were considerable differences between familiarity with shows from different countries, ranging from $57.1 \%$ familiarity with Chinese shows, to $12.6 \%$ of Japanese shows. At 3.94 (out of 5), appreciation of shows was quite high on average 1. Table 2 shows the best-known and the least-known shows, as well as the best-liked and the least liked shows. The Chinese shows are both the best-known, and the best liked. This preference for local television programs,

\footnotetext{
${ }^{1}$ Indeed, the incidence of low scores (1 and 2) in the questionnaire is remarkably low. This might point to a more general cultural pattern, where Chinese are more likely (compared with, for instance American, Dutch or French) to say they don't know than to explicitly express dislike.
} 
the so-called "cultural discount", is an established finding in studies of transnational television (Sora 2004; Straubhaar 2007). However, this preference for the local does not match our expectations regarding a "chain of disdain". The low appreciation for Hong Kong and Korean shows does supports the popular discourse of the "chain of disdain": shows produced in the large and popular cultural industries of Korea and Hong Kong are most looked down upon.

We use the MCA to uncover taste patterns in the liking of series. As we discussed above, the MCA analysis is based on the ratings for all shows that were known by more than $25 \%$ of respondents. We recoded all scores to three modalities: dislike or indifference (1-3 on a 5-point scale); like (4-5 on a 5-point scale), and unfamiliar. On the basis of the scree plot and the inertia (=explained variance) of this MCA, we selected a solution with 3 dimensions. Note that the explained variance is not very high $(12.2+6.9+4.6=23.7 \%)$, which is quite typical for MCA. However, it may also be the result of the rather homogeneous sample, consisting entirely of students born within five years from one another; combined with the rather narrow focus on television shows.

Table 2: best and least known, and best and least liked shows

\begin{tabular}{|c|c|c|c|}
\hline 10 best and least known shows & $\begin{array}{c}\text { Familiarity } \\
(\%)\end{array}$ & 10 best liked and least liked shows & $\begin{array}{l}\text { Appreciation } \\
\text { (1-5 scale) }\end{array}$ \\
\hline Average familiarity & $\begin{array}{c}33 \% \\
(19.5 / 60)\end{array}$ & Average appreciation & 3.94 \\
\hline Journey to the West $(\mathrm{CH})$ & $97.54 \%$ & Sherlock (UK) & 4.40 \\
\hline My own swordsman $(\mathrm{CH})$ & $96.55 \%$ & Journey to the West $(\mathrm{CH})$ & 4.39 \\
\hline Sherlock (UK) & $86.70 \%$ & My Own Swordsman $(\mathrm{CH})$ & 4.38 \\
\hline Duke of Mount Deer $(\mathrm{HK})$ & $78.33 \%$ & Nirvana in Fire $(\mathrm{CH})$ & 4.27 \\
\hline You who came in from the starts $(\mathrm{KR})$ & $77.59 \%$ & Legal High (JP) & 4.15 \\
\hline Return of the Condor Heroes (HK) & $77.83 \%$ & Lurk (JP) & 4.13 \\
\hline Great Jang (KR) & $72.41 \%$ & Reply 88 (KR) & 4.06 \\
\hline Nirvana in Fire $(\mathrm{CH})$ & $70.94 \%$ & Black Mirror (UK) & 4.05 \\
\hline Friends (US) & $69.95 \%$ & Friends (US) & 4.04 \\
\hline Ode to Joy $(\mathrm{CH})$ & $68.72 \%$ & Game of Thrones (US) & 4.01 \\
\hline$* * *$ & & $* * *$ & \\
\hline Detective Investigation Files (HK) & $12.81 \%$ & War of the Genders (HK) & 3.29 \\
\hline Ivory Tower (JP) & 11.82 & You Who Came in From the Stars (KR) & 3.29 \\
\hline Border (JP) & $10.83 \%$ & My Date with a Vampire (HK) & 3.29 \\
\hline Regret from My School Days (JP) & $10.34 \%$ & Juhan Shuttai! (JP) & 3.28 \\
\hline Mission Noir (KR) & $9.85 \%$ & Princess Atsu (JP) & 3.21 \\
\hline Tamiou (JP) & $9.85 \%$ & Skins (UK) & 3.13 \\
\hline Princess Atsu (JP) & $8.13 \%$ & Parks and Recreations (US) & 3.10 \\
\hline Boss (JP) & $8.62 \%$ & Heard It Through the Grapevine (KR) & 3.04 \\
\hline The Election (HK) & $6.65 \%$ & The Election (HK) & 3.04 \\
\hline Heard It Trough the Grapevine (KR) & $6.90 \%$ & City Hall (HK) & 3.00 \\
\hline Per country (ranked best to least known) & & Per country (ranked best to least liked) & \\
\hline China & 5.71 & China & 4.09 \\
\hline US & 3.71 & UK & 4.08 \\
\hline UK & 3.22 & US & 3.85 \\
\hline South-Korea & 2.98 & Japan & 3.79 \\
\hline Hong Kong & 2.63 & Hong Kong & 3.65 \\
\hline Japan & 1.26 & Korea & 3.59 \\
\hline
\end{tabular}




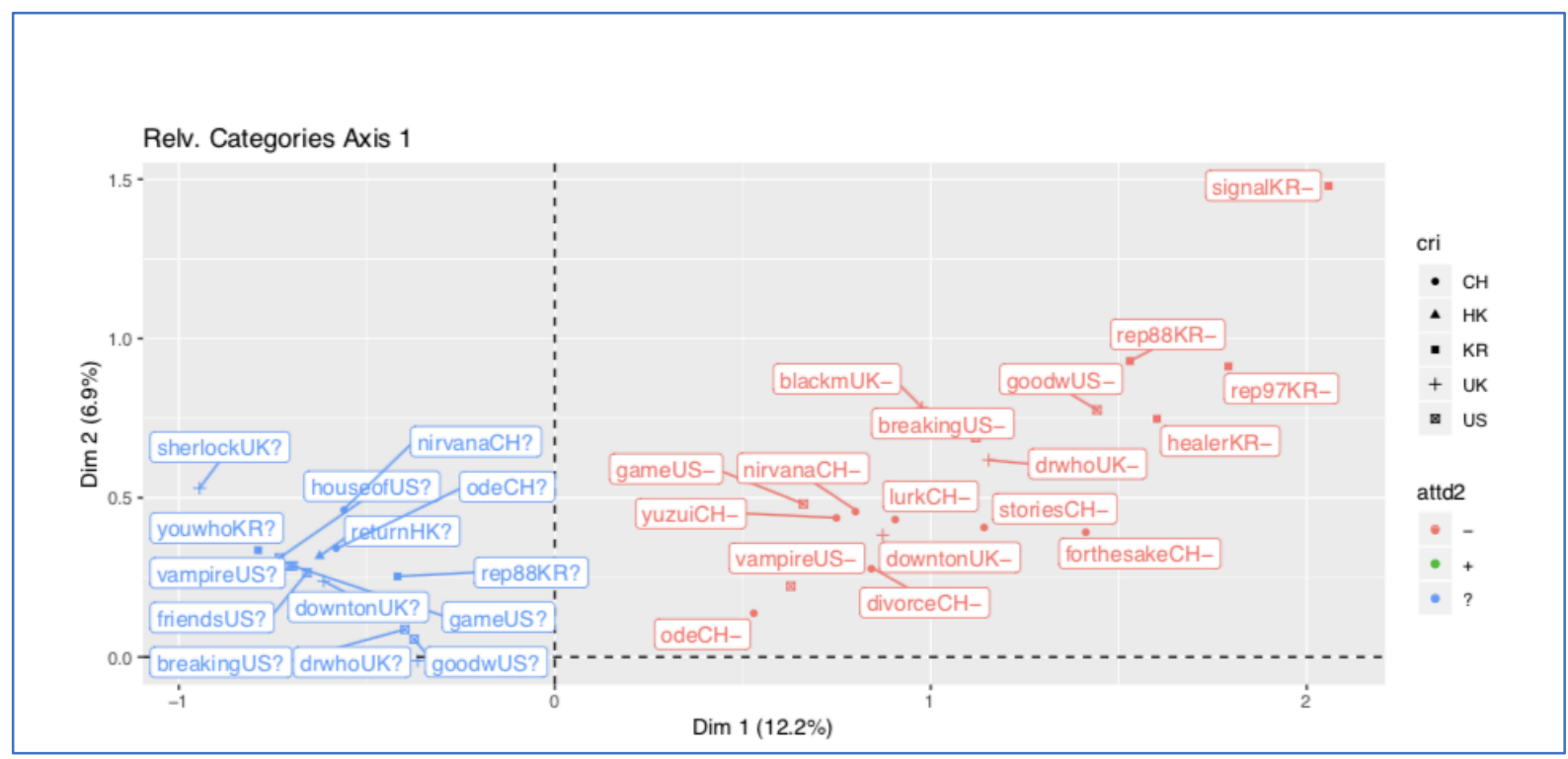

Figure 1: Coordinates of most-contributing modalities on dimension 1: "not-knowers"[-] versus "dislikers" [+]. A name of a series followed by "?" means don't know; a name of a series followed by "_” means dislike or indifference (1-3 on a 5-point scale), a name followed by “+" means liking (4-5 on a 5-point scale).

\subsection{Dimension 1: Not-knowers versus dislikers}

This first dimension, shown in Figure 1, separates informants with a lack of knowledge of a number of wellknown shows (left in figure, or negative scores), from informants who dislike or are indifferent towards shows of various genres and national origins, with a particular dislike vis-à-vis some Korean shows. This means that this dimension has little to do with appreciation or preference. This is a classical Bourdieusian pattern: it separates those who lack cultural knowledge, from those who know about culture but reject. Dislikes, or "boundary drawing", typically is a stronger driver of cultural distinction than preferences or liking (see also Friedman \& Kuipers 2013)

Interpretation of the MCA is typically done by looking at the "most contributing" modalities, or the values for variables that are most important in defining a specific dimension (Greenacre \& Blasius 1984). The most contributing modalities on the left pole are all related to unfamiliarity with very well-known shows: over half of informants know them, in some cases much more. Here, we find all well-known American and British shows (Friends, Black Mirror, Sherlock, Game of Thrones), but also famous and acclaimed Korean (fantasy soap You Who Came In From The Stars) and Chinese blockbuster shows (Ode to Joy, Nirvana in Fire). This pole, then can be described as unfamiliarity with "must know" shows.

This lack of knowledge is opposed to dislike or indifference (1-3 on a 5-point scale) vis-à-vis critically acclaimed shows. Most contributing and highest-loading here are the dislike of Korean comedies Reply 88 and Reply 97, and Korean crime shows Signal and Healer. Neither show is very well known among our informants, but they are widely considered relatively good Korean shows. Informants scoring high on this pole also dislike some well-known and popular Chinese, American and British shows. Interestingly, this dislike or indifference 
particularly regards shows that are considered "quality shows": no soaps or star vehicles, but classics (British SF classic $D r W h o$, first ever Chinese sitcom Stories of an Editorial Board) or acclaimed "modern" shows (Ode to Joy, also dubbed the Chinese Sex and the City, Downton Abbey, The Good Wife). A second analysis of this dimension including the supplementary variables -- that is: the shows known by less than 25 per cent of informants -- does not yield a very different result (no picture shown). Japanese and Hongkong shows "behave" like the Korean ones: people who dislike Korean TV also dislike Japanese and Hong Kong shows. At the negative pole, unsurprisingly, we see an even larger clustering of "unknowns", although unfamiliarity with lesser known shows is scattered more widely across this dimension.

To interpret these patterns, we turn to the interviews, starting with the highest and lowest ranking respondents on this dimension. Our interviews suggest that the negative pole on this dimension is associated with limited cultural interest or highly specific "niche" taste, whereas people ranking highly positive on this dimension are typical "TV snobs" who are well aware of cultural offerings but find many things falling short of their high standards.

A "not-knower" with a strong negative score on this dimension is \#89, a young man born in 1995 (age 21 when interviewed). \#89 grew up in a prefecture-level city (Heze, Shandong province), an eastern Chinese province on the Yellow Sea. \#89's mother has a high school degree, and has stayed at home for years since being laid off from a state-owned enterprise. His father has a college degree and works for a local newspaper, though \#89 is uncertain about what his father actually does. With the lowest score on dimension 1 (-2.10), \#89 is a typical "not-knower." He reports spending about 10 minutes a day watching various TV programming. Although he ranks UK TV as his favorite, followed by US TV (His ranking of TV shows from the six countries is: UK > US > Korean > Japanese > mainland Chinese > Hong Kong), he has not seen much of either. Specifically, \#89 has only watched two US shows: The Walking Dead and Z Nation. Even though he knows little about TV, he subscribes to the notion that Western television is generally the best. When asked about his favorite UK shows, he says:

I've watched very few British shows, and have never watched one from the beginning to the end. I've seen one or two episodes of Downton Abbey, but wasn't very into it despite the good reviews. I've watched one episode of Sherlock. That's a UK show, right?

Responding to the interviewer's question about his ranking UK TV without watching much of it, \#89 says:

Part of it is general opinion. Everyone says British shows are good, so I would naturally have better expectations and impressions of them. 
This informant accepts the quality and legitimacy of things he is not personally familiar with, which is a typical pattern for people with low cultural capital (Bourdieu 1984; Kuipers 2006). He explains his lack of familiarity with TV from lack of time. He reports not having much leisure time, spending his spare time reading comic strips online.

\#187, female, was born in 1997 in Beijing. Her mother holds a bachelor's degree and works as a manager in a travel agency. Her father has a master's degree and chairs the board in an investment company. Thus, with a score of -1.023 on the first dimension, \#187 is a "not-knower" with greater cultural capital than \#89. \#187 is unfamiliar with the vast majority of the 60 selected shows. That said, she is quite positive towards the shows on which she does have an opinion. This may be explained by her selectivity in watching TV:

I've only watched the good [US shows], which is probably why I ranked US TV high. For example, I think. House of Cards is pretty good. I've also watched Breaking $\mathrm{Bad}$ and really liked it. American shows explore a broad range of subject matters, like crime, politics, and other topics that Chinese TV tends to tiptoe around. The acting on American shows is also superb. I feel that British shows are on par with American shows, but I seldom watch them. I've only watched Black Mirror.

Despite her high regard for US and UK TV, \#187's favorite is Japanese TV:

Japanese shows have unique perspectives; they focus on everyday life. US and UK shows tend to be more magnificent, even fantastic. In comparison, Japanese shows seem mundane, but they feel more natural, realistic, and warm. Perhaps because we share a common Asian culture, I really like Japanese shows.

Although both \#89 and \#187 are "not-knowers," the interview data suggest that their unfamiliarity with TV is due to different reasons. In a sense, \#89 is a "truer" not knower, who disengages with TV although he accepts others judgments of its quality. His lack of knowledge about TV is due to lack of consumption of it, and he relies heavily on others' opinions in ranking TV. \#189, on the other hand, is a selective television viewer. Like \#89, she accepts the superiority of Western TV, even when she known little about it. However, her unapologetic preference for the "everyday life" aesthetics of Japanese programming, combined with general avoidance of television, sets her apart from critical "dislikers".

On the other end of the spectrum, we see "dislikers" such as \#169, male, born in 1995 and raised in Wuhan, the capital of Central China's Hubei province. \#169's mother teaches Chinese in primary school, and his father teaches Chinese in middle school. The father has a bachelor's degree for formal higher education, and the mother holds a bachelor's degree for adult higher education. With a score of 1.345 on dimension 1, \#169 is "disliker." Ranking UK and US TV on top and mainland Chinese TV at the bottom, \#169 holds strong opinions about both his favorite and least favorite TV: 
Domestically-produced Chinese TV shows are hit and miss, but in general, they must be ranked lowest... The whole Chinese $T V$ industry is problematic. There are excellent series, to be sure, but the overall quality of production is very poor-so many shoddy shows, so few good screenwriters. The production is fast, like a streamline. And nobody bothers to create something like Game of Thrones for the Chinese market, because there is no need. A lousy movie churned out by people like Guo Jingming*2 based on a trite plot and stuffed with bombshells and heartthrobs would still be propped up by a colossal teen fanbase. I think we are in an environment where the pursuit of entertainment is relentless, so, very few people put real effort into creating quality scripts. The whole TV industry is rotten, and it's the audiences who suffer.

\#169's passion for his favorite show Game of Thrones is as intense as his contempt for mainland Chinese TV. He began watching Game of Thrones in 2015 and liked it so much that he bought both the English and Chinese versions of the book series it is based on:

I prefer shows that are a bit more complicated. The Big Bang Theory isn't my favorite type; it's just a change of pace. I've always liked historical dramas. The way the story unfolds in a historical drama feels delightfully complicated and realistic. For example, the storyline of Game of Thrones is very complex. The six seasons so far involve many kingdoms and a buge number of characters; the whole story has the feel of Romance of the Three Kingdoms. ${ }^{3}$ Following such a complex storyline, you feel as though you really step into that world or that era. I relish this experience; it reminds me of my childhood experience of watching Chinese historical dramas.

This respondent flaunts his cosmopolitan capital by stressing the important of seeing the "authentic" original version, with subtitles:

One must watch shows like Game of Thrones with the original English soundtrack; it feels more authentic this way. It's not a problem as long as there are subtitles. I always make sure to download Chinese-English subtitles. They belp me understand English idioms and gain historical knowledge.

\#169's categorical ranking of shows from six countries is as follows: UK > US > Japanese > Hong Kong > Korean > mainland Chinese. His recognition of UK as the "best" television is grounded in wide cultural knowledge. He draws boundaries on the basis of his cultural taste, dismissing others who do not share his taste and even claiming that he "cannot understand" the cultural life of the majority of Chinese.

Chinese movie-goers in general are not very cultured... Naturally, people's appreciation skills start off low. Only through repeated exposures to good works and constant reflections upon those works can people improve their tastes. The university

${ }^{2}$ Guo Jingming is a popular and controversial pop fiction writer who has branched out to writing and producing TV series and movies. Interviewees who mentioned Guo Jingming unanimously deride him, using him as both a symptom of and a culprit for China's highly commercialized and entertainment-centered popular media industry.

${ }^{3}$ One of the four acclaimed Classical Chinese Novels. 
students you are speaking with are only a small portion of the Chinese audiences. In fact, the majority of Chinese audiences come from tier-two and tier-three cities. These include my hometown, where many people have never gone to college, let alone watching British or American TV shows. From your perspective, their tastes might be incomprehensible. Even for me, when I go back, I feel I can no longer understand their cultural life.

\#169's criticism of mainland Chinese TV and his embrace of quality TV such as Game of Thrones resembles distinctive discourse as we know it from Western contexts and cultural genres. In this narrative, depth and complexity are key in setting quality TV apart from TV that is simply for entertainment. "Good" TV should be complicated and immersive, requiring active engagement and cultural knowledge to be understood and appreciated. "Bad" TV, in contrast, tends to be predictable, unoriginal, understandable to all, as articulated by another disliker, \#321:

Korean dramas are too tropey. All Korean shows must have a steely-eyed male lead and an extremely unfortunate female lead. There must also be a supporting male character who drives a luxurious car and is waiting downstairs for the female lead no matter what time it is. Then, there will be a second female character who's obsessed with the second guy, madly jealous of the first girl, and will do anything to snatch the guy. It's always like that!

\#321, male, was born and raised in Xi'an, the capital of Shaanxi Province in central China. His mother is a nurse and his father a prosecutor. Like \#169, \#321 contrasts with the "not-knowers" on this dimension by having firm, negative opinions on specific shows. That said, both dislikers are also enthusiastic about certain shows: either US or UK TV. Resembling \#169's passion for Game of Thrones, \#321 loves the British political satire Yes Minister, the subject of cult adoration in Britain and America, but definitely not for every Chinese viewer. He also has this to say about Sherlock, the British rendition of Sir Arthur Conan Doyle's beloved mystery tales:

I think Benedict Cumberbatch acts really well. He draws the audience in with his performance. Every expression, action, and word is well-placed. He simply commands all my attention. And sometimes, he conveys even more when he does not speak. His body language makes you think deeper about the meaning of what he's said before, and what's going to happen next. It's such a good show!

These "dislikers" resemble to the cultural "snobs" we know from US and European contexts: they enjoy hard to access cultural goods to distinguish themselves from others, and speak in depreciating tones about the lowly cultural preferences of others. Moreover, the cultural rankings embodied by these "dislikers" are accepted by others. Both "not-knowers" accept the superiority of the shows the dislikers (claim to) truly love. Moreover, 
their tastes mirror the widely shared notion of a cultural "chain of disdain". Thus, this dimension reflects a taste hierarchy accepted even by those who are not "in the know".

\subsection{Dimension 2: TV lovers versus TV avoiders}

The second dimension contrasts people who like a wide range of American, Korean, Hong Kong and Chinese shows, with people who dislike several well-liked American, British, Korean and Chinese shows. They differ from the "dislikers" in Dimension 1, however, because they dislike more mainstream shows like Sherlock, and reporting unfamiliarity with a number of well-known shows, such as Chinese blockbuster Nirvana in Fire. As Figure 2 shows, the "like" pole is not associated with a single dislike, whereas the "dislike" pole is not associated with a single positive evaluation of any show. Thus, this dimension reflects a general liking (or not) for television. Further analysis of shows dropped from the analysis shows a similar pattern: a contrast between "like" and "dislike" that spans all genres and countries.

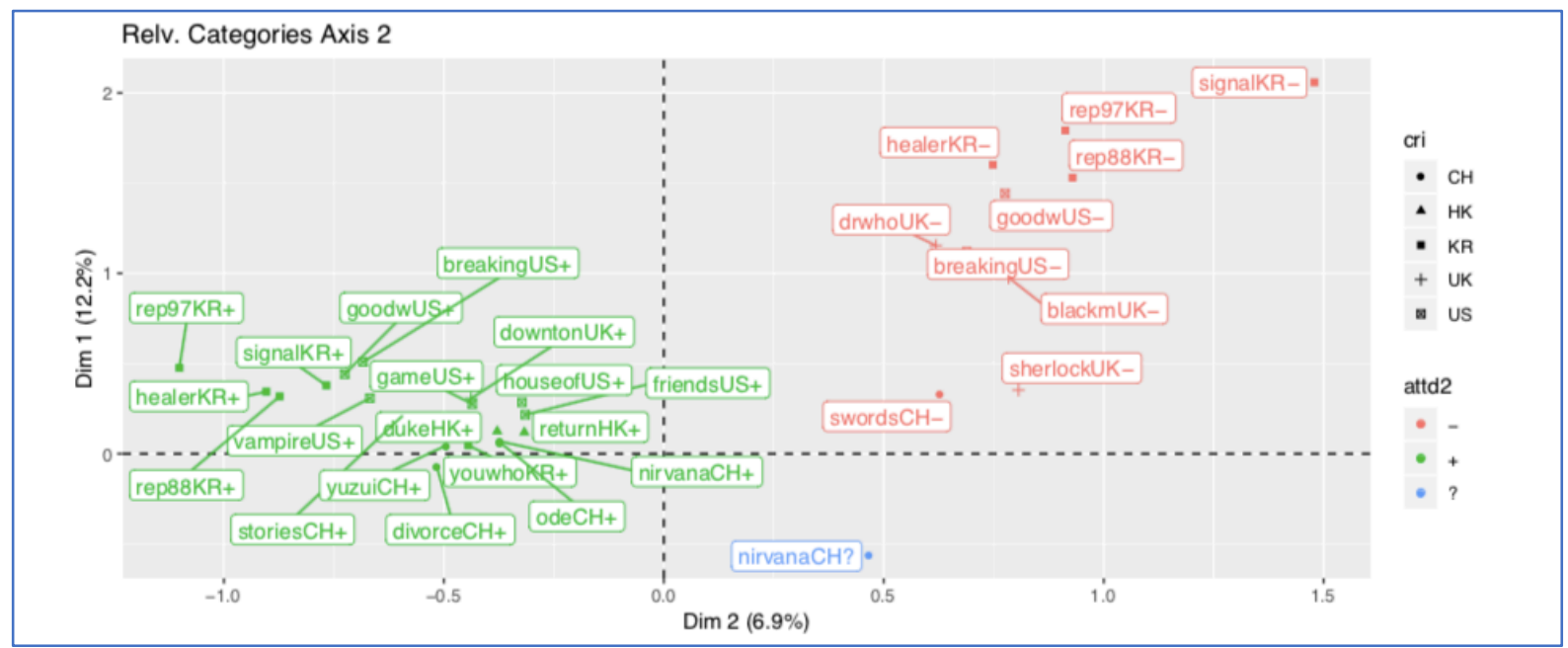

Figure 2: Coordinates of most-contributing modalities on dimension 2: "TV lovers" [-] versus "avoiders" [+]. A name of a series followed by "?" means don't know; a name of a series followed by "-" means dislike or indifference (1-3 on a 5-point scale), a name followed by "+" means liking (4-5 on a 5-point scale).

\# 222, female, was born in 1995. \#222's father has a master's degree and is an administrator in a private university in Hangzhou, the capital of Zhejiang Province. Her mother has a college degree and used to teach chemistry in a high-school in Inner Mongolia before the family moved to Hangzhou; her mother is now a librarian in the same university where her father works. \#222 has a score of -1.302 on dimension 2, making her a typical "TV junkie" who loves to watch all types of TV. She readily recognizes her usual passion for television:

I may be a little different from the average person. I need to watch shows every day. If I'm preoccupied with my studies at bed time, I'll be too exhausted to fall asleep, so I watch shows to relax a little before going to bed. During the semester, I probably 
spend 2-3 hours a day watching shows. Sometimes I spend the whole weekend binge watching. During breaks, I'd just lie on my bed and watch shows from the moment I wake up till I'm ready to go to bed.

Although \#222 has a broad taste in TV, she favors Japanese shows the most, followed by US and UK shows:

I mostly watch Japanese shows. In addition to Legal High, I love Hanzawa Naoki-it's superb! There are so many good Japanese shows, like Kazoku no Katachi, 99.9: Criminal Lawyer, and the recent We Married as Job. I haven't missed an episode! My second favorite is US shows... I just finished watching Westworld two days ago. Have to admit it's a bit too much for my taste. But the special effects look very cool and natural. Many American shows are like that. And special effects on Japanese shows are also well done. In comparison, the quality of special effects on Chinese shows is lower and they look very fake. This could be related to budgets and other resources. You can't make good special effects without money.

\#222 goes on to discuss many shows, including well-known series as The Big Bang Theory, Game of Thrones, and House of Cards. What stands out about her passion for TV is not only her broad taste in TV, but also her ability to evaluate a show in a dispassionate way. Westworld might cause certain emotional or moral discomfort for \#222, but she is able to assess the show by focusing on its formal characteristics such as special effects.

This tendency to talk about television like a "connoisseur" is common among TV lovers. These individuals tend to be knowledgeable about technical matters in TV making. Many of them rely on the internet and social media to learn technical terms and identify new shows worth pursuing. For example, \#69, female, born in 1994, discovered her favorite show Shameless by reading a comparison between the British and American versions of the series on Douban:

I was intrigued and decided to give the show a try. At first, I thought the show would be interesting precisely because it's about a world that was very different from my own. But the more I watch Shameless, the more I'm impressed with how masterful it is in rendering the unfamiliar so recognizable... For example, on the show, whenever things seem to be looking up is exactly when they'd suddenly take a turn for the worse. Life is cruel like that. You bit rock bottom, but you have to keep on living. It's very realistic and different from all those pandering sap-fests on TV.

\#69 also speaks highly of "quality" local shows:

To me, Nirvana in Fire 4 is a quality show. I wasn't much into local shows in the past, but after watching Nirvana in Fire, I've been on a local shows kick... To begin, its costumes and props were meticulously designed. Many posts on Zhibu and Douban said that the costumes were historically authentic, very different from the bideous, macaron-colored costumes in every other period drama. Costumes aside, its special effects and other details were well executed. The show's success put its producer

4 The titular novel on which the show is based is known as the Chinese The Count of Monte Cristo. 
Shandong Film and TV Group on everyone's radar. The Group is synonymous with quality Chinese shows, and everyone has high hopes for their future productions. In terms of acting, Wang Kai and Jin Dong were not as famous as the leading actor $\mathrm{Hu} \mathrm{Ge}$ when the show just came out. However, they were all great actors, very expressive and relatable. And finally, the plot is fast-paced, exhilarating, and never draggy.

To \#69, quality TV is not so much marked by country of origin or even by subject matter as it is defined by technical characteristics. Like \#222, and echoed by others with high scores on dimension 2, \#69's interest in watching TV goes beyond enjoying a good story. She relishes watching TV as much as she does researching it. To TV lovers like \#222 and \#69, television bears pedagogic value and a chance to become and "expert" in a field, on top of values of escapism or entertainment.

Contrasting with this general liking of TV is a general dislike of television that includes popular international and Chinese shows. Take \#285, a sophomore in history, who has the highest score of 2.874 on dimension 2. \#285 was born and grew up in a prefecture-level city. Both of his parents are high-school graduates. His mother has retired from a wood factory, and his father is a bus driver. \#285 rarely watches TV shows in college, reporting no more than 2 hours spent on watching TV each week. He is generally nonchalant towards TV shows, even those that are the talk of the town. Speaking of the wildly popular Korean romantic fantasy You Who Came from the Stars, he says:

I've heard of You Who Came From the Stars, but haven't really watched it. (Interviewer: Why not? Aren't you interested?) Not really. A common problem with Korean dramas is their dragging plots. A show can last a thousand episodes! There's too much fluff, like, plots that are there just so the show can go on.

Three of \#285's five roommates are big fans of The Big Bang Theory, and they watch the show on their respective laptops every day in the dorm. When asked if the roommates' passion has intrigued him to check out the show, \#285 responds:

I've taken a few glances when they watch the show.

Interviewer: Just a few glances? Why not more?

In part because I'm not interested, in part because I don't have time. Well, mostly because I don't have time. I rarely watch TV these days.

Interviewer: You mentioned that you only spend 1 to 2 hours a week watching TV.

That's probably overestimated, come to think of it.

Interviewer: When you do watch TV, what do you watch?

Mostly older Chinese shows. I've been watching Yearnings lately, when I have time.

What about popular foreign shows, like House of Cards and Game of Thrones? 


\section{I haven't seen either. \\ Do you plan on watching either? \\ Maybe, if I have time, but I doubt it.}

Although these "avoiders" report many dislikes, they are actually more like the "not-knowers" than like the "dislikers" on the first dimension. While the dislikers have strong and elaborate opinions on both the shows they dislike and like, avoiders' low opinions on TV are general and nonchalant. Lack of time is the most-cited reason, which suggest indifference rather than active dislike. Take \#98, who has the second highest score of 1.668 on dimension 2. \#98's favorite TV genre is the sitcom. He ranks US TV the highest, followed by Chinese TV, mainly because he has watched few shows from other areas. \#98 does not have time to watch any TV during the semester. During breaks, he watches American sitcoms, including Friends, How I Met Your Mother, Modern Family, 2 Broke Girls, and The Big Bang Theory. When asked about other popular US shows such as House of Cards and Game of Thrones, he says:

I've tried both, but couldn't watch either for longer than a few minutes. (Interviewer: Why?) I don't know; I just don't like their vibes. Oh, right, I've seen a few episodes of The Walking Dead. It's pretty long: an episode is like 70 minutes or something. I really don't have big chunks of time like that, so I'm not watching it anymore.

In contrast with TV lovers, who are extremely articulate, avoiders give flat, non-committal responses. However, their disengagement differed from the disengagement of not-knowers. The not-knowers' lack of knowledge coincided with a clear awareness of cultural hierarchies in television taste, and a recognition that some shows were "good" even if personally they didn't watch them. Dimension 2, then is about engagement with television, but it differs from Dimension 1 in being not hierarchical or exclusive. TV lovers like all TV, quite indiscriminately. They do not draw boundaries on the basis of TV taste, nor do they take others to task for not sharing their preferences. TV avoiders, their counterparts simply do not care. No boundary-drawing appears to be going on on either side of this dimension.

\subsection{Dimension 3: A taste for the East versus a taste for the West}

The third dimension, finally, reflects a taste variation related to the origin of shows. Respondents with negative loadings like American and British shows, and - interestingly - the 2003 Chinese historical drama For the Sake of the Republic, which rather realistically documents the beginning of the Chinese republic in the early $20^{\text {th }}$ century. These informants tend to be unfamiliar with well-known shows from China, Korea and Hong Kong. On the other side of the same pole, we find people with a preference for Korean shows, but also Ode to Joy, a Chinese series that is often compared to Sex and the City. These people are unfamiliar with recent American and British series, and dislike the above-mentioned (rather serious) For the sake of the republic, and Chinese spy thriller Lurk. 
Thus, this dimension shows a distinction between two types of international, and maybe cosmopolitan, tastes: a Western taste that avoids Asian TV, and an Eastern/Korean taste that avoids Western (and some Chinese) fare.

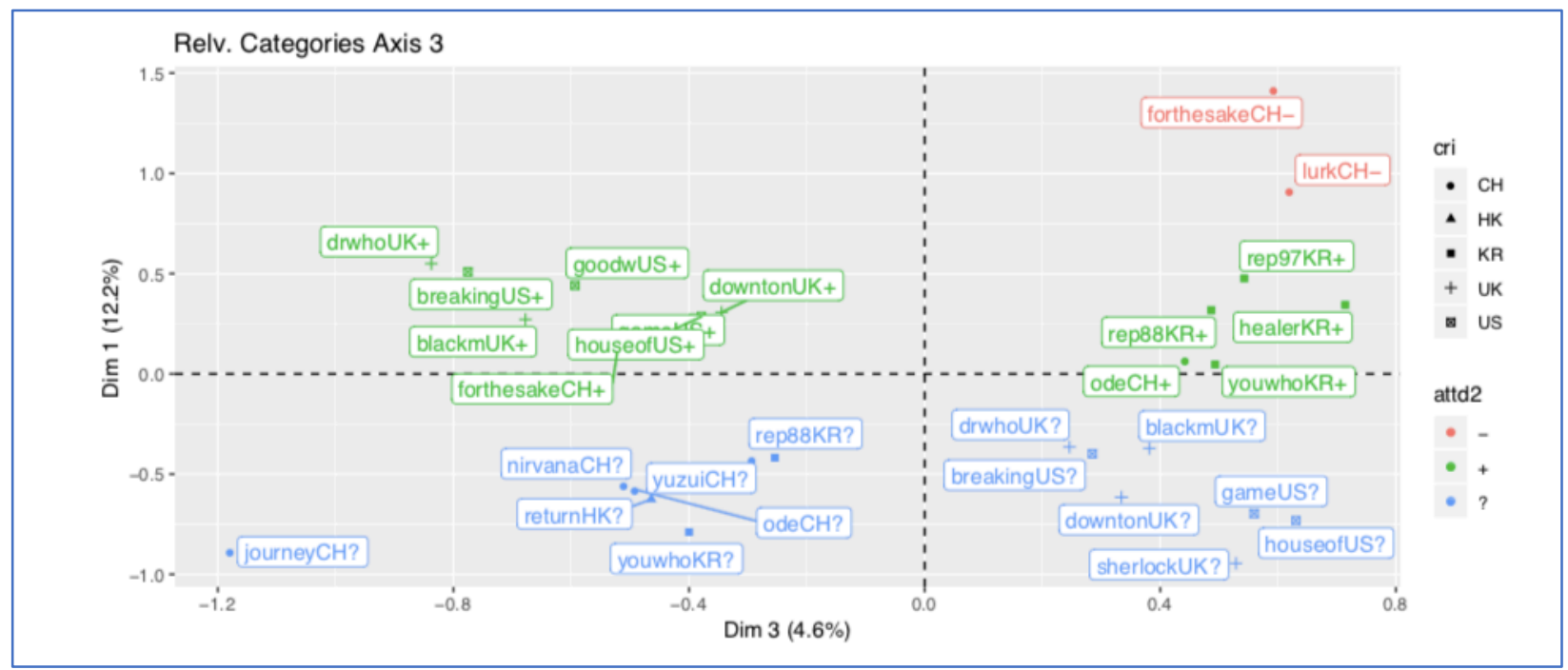

Figure 3: Coordinates of most-contributing modalities on dimension 3: "Western" [-] versus "Eastern" [+] taste. A name of a series followed by "?" means don't know; a name of a series followed by "." means dislike or indifference (1-3 on a 5-point scale), a name followed by "+" means liking (4-5 on a 5-point scale).

Further analysis of the shows known by less than $25 \%$ of the sample yields an interesting surprise: the preference for Japanese shows (who were typically known by less than $25 \%$ ) cluster to the left, with the Western shows. The exceptions of Princess Atsu (a historical drama) and My Dangerous Wife (a crime show). People with an "Eastern" taste tend to dislike most Japanese shows. Moreover, preference and dislike of Hong Kong and Chinese shows are scattered across this dimension, suggesting that, from the perspective of this dimension, the like of dislike of these shows is a matter of style and genre, not so much of origin. The American and British shows show a consistent pattern: likes to the far left, unknowns to the far right of the figure.

The "Western" taste is epitomized by \#186, a sophomore in sociology who grew up in Liuyang, a county level city in Hunan Province. Both of \#186's parents hold a junior college diploma, and they both work in the Party and Administration Office in public institutions. \#186 watched the British teen drama Skins in high school and loved it. Like many other interviewees, \#186 use Douban to find out about new shows to watch:

I saw Skins on a few 'must watch' lists on Douban... The synopsis and posters attracted me, so I downloaded it. It's a teen drama about a life very different from my own, very exciting and interesting. I was quite addicted to it; sometimes I would stay up late to watch it on my phone in bed. 
\#186 talks about how he was impressed with Skins for being "bizarre" and "absurd" while being so "real" at the same time.

Its authenticity isn't about how close it is to my life, but about how its director, actors, and production crew work together to make the show convincing on different levels, such as the arrangement of plots and layout of scenes. It makes me feel real, that things like that actually happen in the UK.

Previous research has found perceived realism to be indispensable to the pleasure of watching fictional TV (Ang 1985; Liebes \& Katz 1990). For viewers of foreign television, the "realness" of a show hinges on its ability to render the unfamiliar recognizable and therefore relatable at an emotional level (Gao 2016). In line with that finding, authenticity is also a prominent theme in our respondents' discussion of quality TV, as illustrated here by \#186, as well as earlier on by \#69's in commenting on the "realness" of her favorite show Shameless.

Skins may have opened the door to English language programming for \#186. In high school, he began watching Doctor Who, The IT Crowd, and Game of Thrones. Busier schedules in college have made him more selective in choosing what to watch:

Black Mirror is the only TV show that I'm watching now, because I feel like it's on a completely different level than the other shows I've watched. It has more substance; there are thoughts and ideas in the show that help you reflect on social problems. It's more in line with my status as a college student [laughs]. It's also a very cool show, in terms of its production and looks.

Exposure to Western TV may have shaped \#186's definition of and expectations for quality TV. When asked to discuss what quality TV means to him, he emphasizes certain stylistic characteristics, comparing the recent smash hit Chinese modern Wuxia historical drama Nirvana in Fire and the long-running British science fiction drama Doctor Who to make his point.

Nirvana in Fire was a crowd pleaser when it came out; everyone on WeChat was raving about it. Naturally, I checked it out. And I was done after seeing the first few shots of the first episode. There was a person sitting in a pavilion, gazing at eagles in the sky. The eagles looked so fake and just screamed bad CGI. In comparison, Doctor Who's visual effects are also rudimentary, but at least they don't make you feel like they were made by a computer. For example, those cylindrical robots [The Daleks] look old-fashioned and crudely constructed, but there is something adorable about its physicality, unlike bad CGI that feels especially fake and ugly.

Like other low scorers on dimension 3, \#186 speaks of his appreciation of Western TV with a sense of superiority that sets him apart from others. Sometimes, this is expressed subtly: 
I feel like I have broader horizons than my Chinese friends; I'm not sure if this has to do with my watching more British and American TV shows.

But in directly addressing the "chain of disdain" in TV watching, \#186's becomes more explicit about his sense of distinction. Note that he softens his strongest expression of disdain with laughter.

I feel like everyone has a 'chain of disdain' in their mind; it's actually a kind of ranking for different types of TV shows. I mean, I don't really 'disdain' classmates who watch certain shows, except maybe Korean shows [laughs]. But seriously, I do feel that somehow people who watch Korean shows are 'brainless.' In my high school, those who didn't have good grades tended to like Korean shows; I don't remember a single person with good grades watched Korean TV.

He then pivots to discussing his own favorite show:

Take Black Mirror, you need language proficiency as well as certain outlook and qualities to appreciate this kind of TV. Given this, I can't deny my "disdain" toward my classmates who watch crappy local shows and Japanese anime.

Black Mirror is certainly considered edgy and prestigious by many respondents who are attracted to Western TV. But some individuals on the left pole of the third dimension are drawn to shows that are even more niche. Take \#47, female, a senior in International Politics. \#47 with a high cultural capital background (see below) is a hardcore fan of UK TV. Speaking of her favorite show, The Mighty Boosh (A rather avant-garde BBC3 comedy), she says:

It's a relatively niche British show. But unlike Sherlock and Downton Abbey, its main audience is not outside the UK. The show is very popular in the UK, but rarely known overseas. It's a rather bizarre and mind-blowing comedy.

Ranking British shows on top was a no-brainer to \#47:

[B]ecause I mostly watch British shows. To me, British shows, especially comedies, are uniquely attractive. You may find them not funny at all when you first watch them, because the humor is very subtle. But once you get it you can't stop langhing. Also, there are lots of pop culture and music references in British comedies. And because I'm a fan of many British bands, I can get those references— they feel like inside jokes. I really like that feeling. It's like, I'm in on the joke... In terms of US shows, I haven't watched many. But there seem to be quite a few phenomenal shows on offer. For example, this summer's Stranger Things is one of my favorite; it's a really brainy show.

Despite her enthusiasm for English language programming in general, \#47 has some pet peeves about US TV: 
I don't like the deliberate exaggeration of many US shows. For example, both House of Cards (US) and Yes Minister (UK) are political shows. House of Cards clearly tries to impress you with how awesome and badass its protagonists are. But I really am unimpressed, because it feels like it's all because the opponents are simply too lame! Yes Minister is very different. The British have a wry sense of humor, but once you understand it, it's absolutely hilarious... I don't much like The Big Bang Theory for the same reason; it's too American.

Interviewer: Too American'? What do you mean by that? Just a feeling - that the Americans seem to think of themselves as extraordinary, whereas the British almost enjoy selfdeprecation... I like that they don't seem to take themselves too seriously.

The evolution of \#47's TV taste shows a transition from a "popular distinction" to a more "Bourdieu-style" cultural capital distinction, as her cultural knowledge expanded and developed:

I came to like British shows only gradually. You see, there are two types of British shows: those that are popular within the UK and those that are popular overseas. I started off watching shows that were very popular overseas, such as Downton Abbey and Sherlock. Over time, though, I gradually fell in love with shows that were more niche and more popular within the UK, such as The Mighty Boosh.

Who or what medium first led you to British TV shows?

It might be Weibo. ${ }^{5}$ I started microblogging in high school and followed a few people who were interested in US and UK TV shows, as well as European and American films... Technically, I started off being a fan of US TV rather than UK TV. My first addiction was Supernatural. I was attracted to the premise of the show-it's about two brothers traveling around, catching and busting evil supernatural creatures. I was into the paranormal theme! Plus, the three leads were quite good-looking [langhs]. But the show later devolved into a ridiculous family drama: the brothers abandoned each other, exploited each other, betrayed each other, and then they reconciled. It was very annoying. So, I dropped it.

Like many other pursuers of Western TV, \#47 deliberately avoids local Chinese shows. She singles out Hunan TV — a highly commercialized provincial satellite TV station—for epitomizing a worrisome trend in Chinese TV production. Speaking of a recent potboiler from the station, Yes! Mr. Fashion, \#47 laments:

I was shocked at how there could possibly be such a brainless TV show! The whole show was shot through a pink. filter; the female lead is ridiculously dityy. It's hard to watch! I really resent the role Hunan TV has played in the cultural industry. It has set a very bad precedent, which is that as long as there are celebrity stars in a show, it doesn't matter how stupid the plot is. They aim their shows at teenagers, you know, kids in primary and secondary schools. So there's no need to focus on the

\footnotetext{
${ }^{5}$ China’s most popular microblogging site.
} 
plot; as long as popular actors like Yang Yang or Li Yifeng are in the show, everything will be fine. This rubs me the wrong way.

But \#47 is careful not to paint the picture with too broad of a brush. Like a true highbrow culture lover, she carefully points to the few "good" local shows_-including two included in our survey: Nirvana in Fire and Ode to Joy-for giving her hope for local shows. She also has a level-headed explanation for having various opinions about shows from different places. The reasoning is shared by a few other respondents.

I think part of the reason that I have a bad impression of local shows is that I live here and am exposed to all sort of showsthe good, the bad, and the absolutely unwatchable. In comparison, when it comes to British and American shows, we don't see the bad, or even the mediocre ones; we only see the more popular and outstanding ones. So, of course we have distinct impressions of shows from different places.

As \#47 reflects on tastes for different TV, she deftly reflects on the logics of cultural capital, Chinese style:

Young people and people who are less educated tend to like local shows or popular rom-coms from Korea, such as You Who Came from the Stars. British and American shows are not for everyone. With language and cultural barriers so vast, people with less education might not understand English language programming, let alone enjoy it... In comparison, I think people who enjoy British and American shows have broader horizons. I would guess that their families are also wealthier. But education is definitely the most important factor. My family, for example, doesn't have much money. But my parents are teachers; they are more educated and have more contact with Western culture.

Would you say that your gravity towards US and UK TV is somehow related to your parents?"

Most certainly. My mother signed me up for English lessons when I was very young; she herself teaches English. My father studied Chinese literature in university, and he has always encouraged me to read more literature, not only in Cbinese but also in English, like Shakespeare.

Finally, speaking of the "chain of disdain" in TV consumption, \#47 rather majestically places the blame for other people's bad taste outside themselves, blaming commercialization instead:

I don't think. I 'disdain' them [people who watch bad TV]; it's more like I feel disappointed and exasperated. But I'm really angry at certain TV producers and stations. They are accomplices in pushing China's cultural industry towards a bad direction. They keep churning out shoddy shows, which less sophisticated audiences just lap up!

Here, a taste for Western television emerges as a specific form of cosmopolitan cultural capital (Weenink, 2008; Prieur \& Savage, 2013; Igarashi \& Saito 2014). Partly couched in the same terms as the distaste of the culture 
snobs of dimension 1, these respondents also point to complexity, originality and authenticity. However, the people with Western taste cultivate "rarefied" tastes more explicitly, priding themselves on their knowledge of things unknown to the majority. The strongest boundaries drawing here is not against local culture, but vis-avis a commercialized Asian pop culture that is produced not only in Korea, but also in Hong Kong and by more commercial Chinese producers like Hunan TV. Thus, underlying the East-West opposition is a more familiar, one could almost say Frankfurt-School discourse vilifying commercialized mass culture - with Korean pop culture as the strongest signal. This contrasted with carefully selected Western "quality" shows, but also Japanese shows and "serious" Chinese productions such as For the Sake of the Republic, that symbolize good television.

Their counterparts are the lovers of precisely this Korean pop culture. \#334, female, DOB 1996 (aged 20 when interviewed), is a junior in sociology. With the highest score of on dimension 3, she is a hardcore fan of Korean drama, and not much into Western shows. \#334 parents are divorced, and both have new families now. She grew up in a small prefecture-level city in Sichuan province with her grandmother. Both her parents graduated from junior high school. Her father holds a low-level white-collar job in a local state institute. Her mother moved to Hong Kong and works in a restaurant there. \#334's regularly goes to Hong Kong to visit her mother.

\#334's categorical ranking of shows from the six different countries is: Korean > Hong Kong > Chinese > US $>$ UK > Japanese. Note that this ranking is almost a complete reversal of the "chain of disdain", and draws the strongest distinction between Korean and Japanese TV. Her passion for Korean TV began when she first saw a Korean show on the computer at her cousin's house:

I didn't have a computer back then, but every time I visited my cousin, she was always watching this Korean show called Boys over Flowers. It was a straightforward Cinderella story. The plot was trite, for sure, but I didn't care. It felt so dreamy back then. And now all I remember is how cute the two leads are [langhs].

\#334 went on to watch a lot more Korean drama, ad nauseam. At some point, she felt that Korean shows were "too cliched and unrealistic." But when she was in the $11^{\text {th }}$ or $12^{\text {th }}$ grade, she noticed a big improvement on the part of Korean drama:

It became more innovative. The main characters are still gorgeous, and that's important, mind you [laughs]. But on top of that, I find the new elements in the shows refreshing. The biggest hit when I was in $12^{\text {th }}$ grade was You Who Came from the Stars. Deep down it's still the same story about the male and female leads falling in love. But in this show, the male lead is an alien, has super power, and never ages. The show is full of suspense and keeps you on the edge of your chair.

Speaking of her impression of Western TV, \#334 emphasizes the distance she feels towards UK and US shows: 
In terms of UK shows, I've only seen Sherlock. It's only got three seasons, nine episodes in total, so it's not too time-consuming. I checked out Sherlock only because I like detective shows, I'm actually not that into UK shows. They feel too up there; I mean, their culture feels so far away from us that I don't really get it. For example, Downton Abbey seems to be everyone's favorite. But not to me! Even the poster of the show turns me off-the traditional clothing seems so stiff and strange. In comparison, US TV feels more down to earth and more diverse... The first US show I watched was Gossip Girl. I was drawn to the completely different lives portrayed on the show. But the more I watched that show, the more I felt their lives were simply too different from ours. Later in college, I asked around for a good show to help improve my spoken English and listening comprehension. Everyone recommended Friends. I liked it. But it's too long; I still haven't finished it. Other than these two, I've watched very few US shows, in part because US TV is generally very long. To commit to a show, I have to be prepared to follow it for ten seasons. I can do two or three seasons, but can't stick to something for that long. (...)

I watched the recent Westworld. It's very edgy and thought-provoking. But it's too hardcore for my taste-too much violence and sex. Americans are too open. There is no way such a show could ever be made in China. And of course, I'll be remiss to not talk about Game of Thrones, which has pretty much been the talk of the town. I didn't see it, because it sounds too grand. I'm not into epic shows. They feel too complex and too far away from now.

Another Korean TV lover, \#11, who has the second highest score on dimension 3, echoes this reason for avoiding US and UK TV:

I rarely watch US and UK TV. UK TV is too draggy for my taste. For example, I don't get why so many people like Downton Abbey. I think it's too long. Each episode lasts forever and is very slow. It's also got a very dull and heavy tone. The whole old-school English gentleman vibe doesn't exactly cheer you up... As for US TV, I've only watched a little bit of Friends; not my cup of tea either. Plus, it's too tiring to watch English language shows-you have to keep an eye on the subtitles all the time!

Interestingly, even though \#334 is put off by the grandness and complexity of UK shows, she explains her renewed passion for Korean shows by emphasizing how more recent Korean shows are more innovative, intelligent, and essentially more like American shows. Here is how she describes a personal favorite, the Korean drama Phantom (2012):

I like Phantom because it's not a typical Korean drama... Most Korean shows are either family drama or sappy romance. That's why people look down upon Korean TV. But Phantom is different; it's a smart show, not just about cute leads falling for each other. In fact, the show is not about romance at all. It's about cyber crimes and contains detective and sci-fi elements, more like US TV. It's more "nutritious" and brainier. I feel smarter watching that show. 
This is a clear reference to a taste hierarchy made by a respondent without prompt. While it may be a stretch to say that \#334 chooses to watch particular TV shows to feel better about herself, the following quote does reveal her self-consciousness about her intellectual capacity. When asked about her plan in four years, she says,

I don't know. I don't think. I'll take the national postgraduate entrance examination. It's too tough; not for me. I hope to get the postgraduate recommendation, ${ }^{6}$ but I also want to change my major.

Interviewer: Why? You are not interested in sociology?

Not that I'm uninterested, but, well, I think sociology is too deep for me. Whenever I'm in a sociology class, especially a theory class, I feel dumb and shallow, as if I don't read enough, or my mind is empty. I feel as though I can only scratch the surface, and I'm not capable of deep thinking. So, I'm not sure if I'll continue studying sociology.

Note that this informant, despite her family's rather low cultural capital, has been accepted into a very good university. However, the tension between the social and cultural hierarchies she has internalized and her engagement with things that touch her personally is quite evident. Her despondent tone, as well as the internal contradiction in her statements regarding her television taste are typical of the alienation or "habitus clivé" (split or cleft habitus) resulting from upward social mobility (Friedman 2016). In her case, her taste has not caught up with her social surroundings, and she seems on the verge of giving up. Although we cannot draw to strong a conclusion on the basis of a single interview, lack of cultural capital may have been part of her sense of alienation and "feeling dumb".

\section{Cultural Capital? TV taste, social background and social prestige}

The analysis above suggests that TV taste in China do indeed function as cultural capital. People have divergent TV taste and various levels of engagement with television. Some tastes are used to express superiority over others, while other tastes reflect submission to, or disengagement with dominant cultural hierarchies. Moreover, these patterns of distinction are related to the regional origin of shows, with Western shows at the top of cultural hierarchies, and Asian and especially Korean ones at the bottom. In other words: television is a site of disdain (and upward aspirations), and this disdain can be said to constitute a widely recognized "chain". But do these distinctive patterns support socio-economic hierarchies? To answer this question, we how look at the relation between our informants' judgements of taste and their social prestige, economic position and familial cultural capital? In the final section of this paper, we analyze the relation between social background variables

${ }^{6}$ Postgraduate recommendation means being enrolled in graduate school without taking the post-graduate entrance examination. 
and the three dimensions. Figure 4 and 5 show the results of the MCA with the main social background variables as supplementary variables projected onto the three dimensions. ${ }^{7}$

We identified the first dimension, of the "not-knowers" (negative scores) versus the "dislikers" (positive scores) as a cultural capital dimension. This is supported by the analysis of social background. This dimension is related to the educational and occupation level of both parents, with not-knowers from distinctly lowerclass backgrounds. Dislikers are also slightly wealthier, self report a higher socio-economic status, and have travelled more, whereas not-knowers have not traveled but would like to. Not-knowers are more often from a rural area. In China, rurality is generally taken as a sign of low social and economic status (Bian 2002). Other differences seem quite marginal: dislikers are somewhat more likely to be male and report better English skills. Even in this homogeneous group of young college students in a single elite university, the dislikers, with their strong opinions and sharp rejections of other people's tastes, obviously come from more educated and prosperous homes.

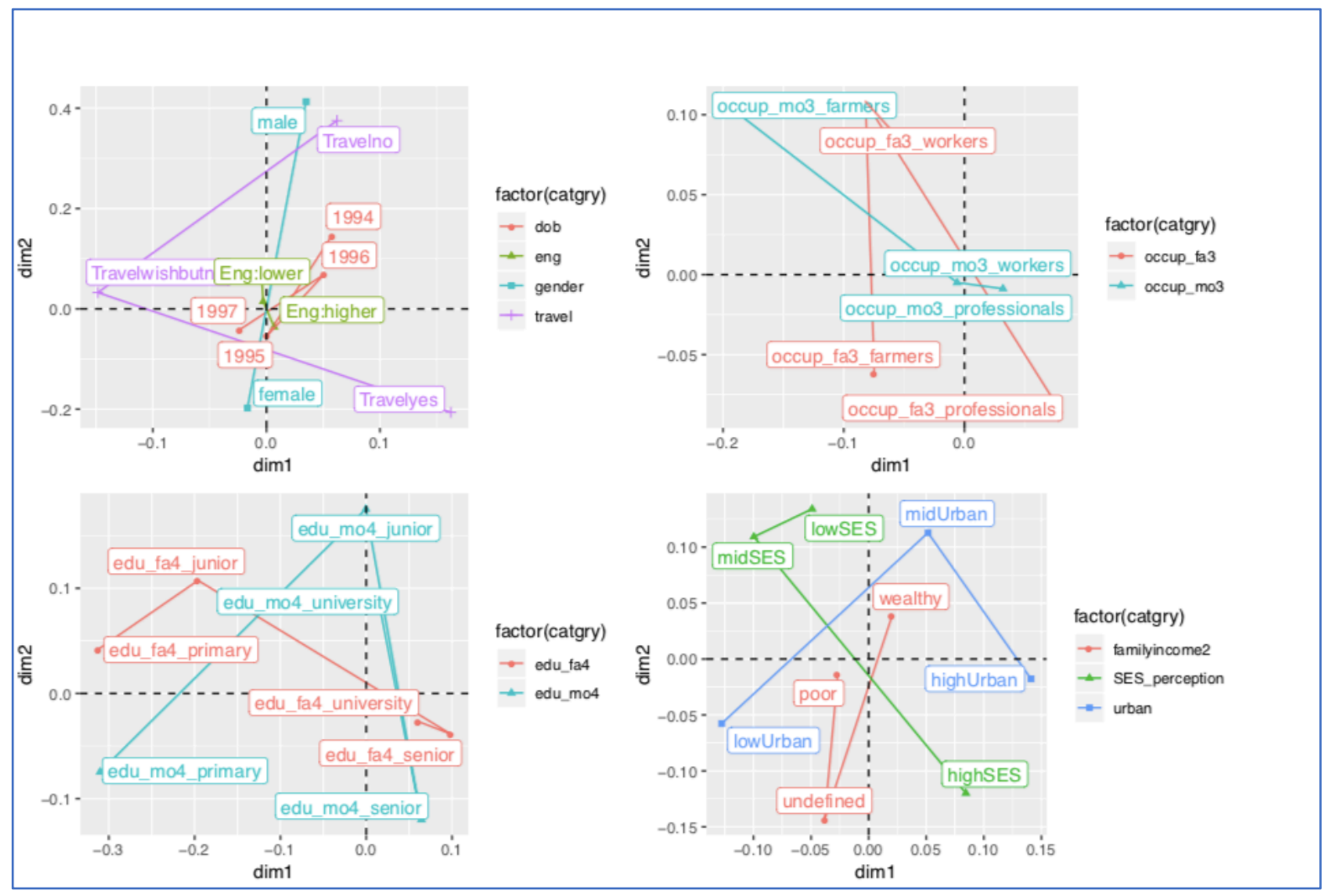

Figure 4. Social background variables and Dimensions 1 (not-knowers [-] versus dislikers $[+]$ ) and Dimension 2 (TV lovers [-] versus avoiders [+]).

Variables 1: Year of birth (dob), has traveled (yes/no/wish but haven't), gender (female/male), level of English (lower/higher) Variables 2: Occupation father (farmer, worker, professional) and mother (farmer, worker, professional)

Variables 3: Education father (primary, junior, university, senior degree) and mother (primary, junior, university, senior degree) Variables 4: Family income (poor, wealth, undefined), perceived SES (low, mid, high), urbanity (low, mid, high)

\footnotetext{
7 To the best of our knowledge, there is no clearly established convention regarding the measurements of social background in China. Therefore, we had to make this up as we went along, basing ourselves on European and US measurements.
} 
The second dimension distinguishes TV lovers (negative scores) from avoiders (positive scores). This dimension is strongly gendered: TV lovers tend to be female, TV avoiders tend to be male. This is striking because it resembles many a wealth of European and American studies were television is identified as a "female" medium (e.g. Olsson \& Spigel 2004). Relations with other background variables are rather hard to interpret: TV lovers have slightly better English skills, have travelled more and report higher SES, but avoiders are more likely to be wealthy. Relations with parental class and education seems quite diverse. These somewhat conflicting findings, however, confirm our interpretation that this dimension does not reflect a status-based taste hierarchy. Instead, it marks a general engagement with television as a medium and pastime that is is especially appealing to women, versus a lack of engagement with television that is more typical of men. Neither orientation seems to be useful as cultural capital. However, it seems plausible that engagement with television does play a role distinctive gender performance or male or female bonding.

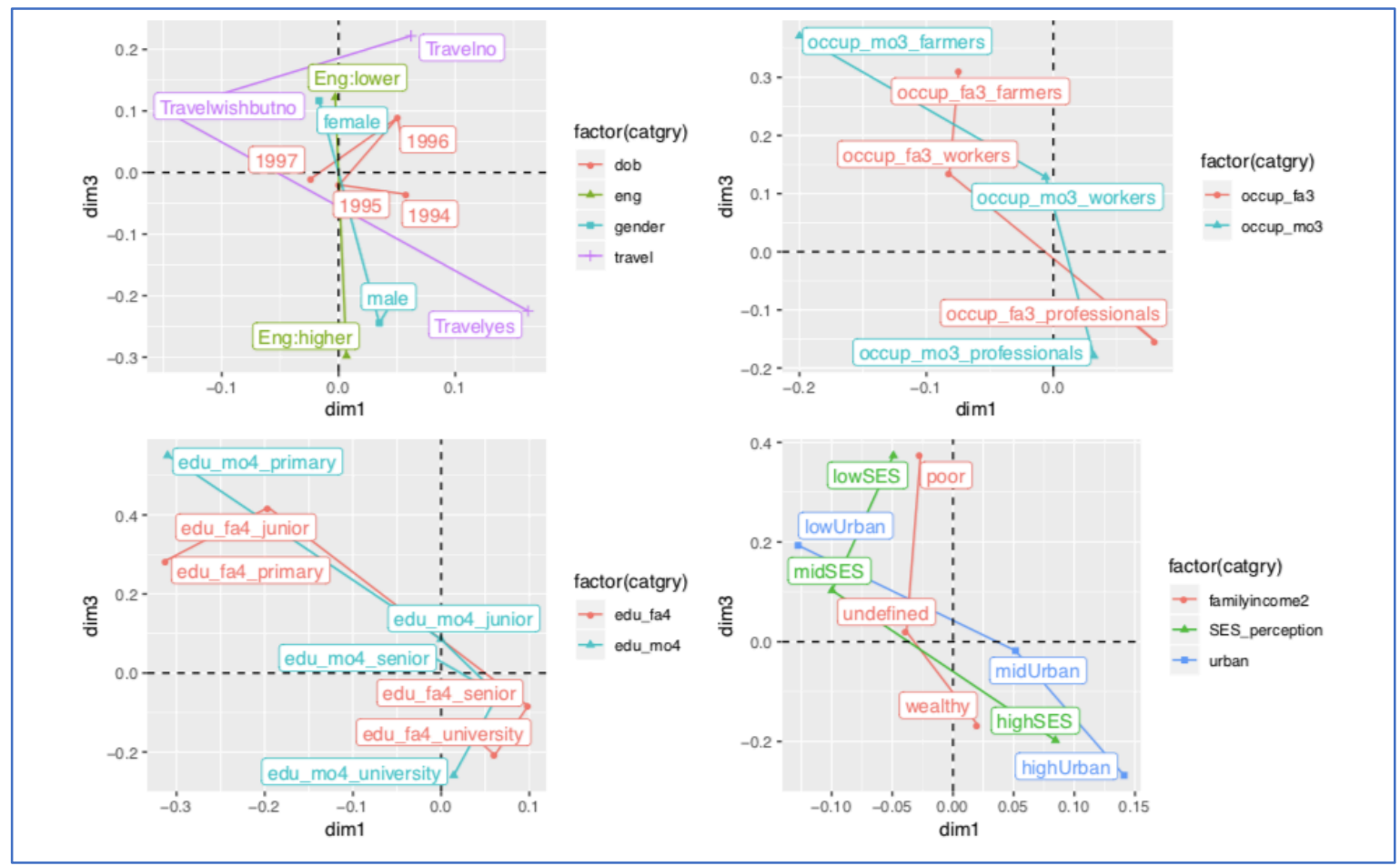

Figure 5. Social background variables and Dimensions 1 (not-knowers [-] versus dislikers [+]) and Dimension 3 (Western [-] versus Eastern [+] taste).

Variables 1: Year of birth (dob), has traveled (yes/no/wish but haven't), gender (female/male), level of English (lower/higher)

Variables 2: Occupation father (farmer, worker, professional) and mother (farmer, worker, professional)

Variables 3: Education father (primary, junior, university, senior degree) and mother (primary, junior, university, senior degree) Variables 4: Family income (poor, wealth, undefined), perceived SES (low, mid, high), urbanity (low, mid, high) 
The third dimension (Figure 5) contrasted informants with a liking for Western (negative scores) and Korean (positive scores) television. As we saw, this dimension came with strong boundary-drawing: the 'chain of disdain' which places Western fare firmly above popular Asian television, in particular shows made in the panAsian pop cultural factories of South-Korea and Hunan TV. Because Dimension 1 and 3 are plotted together, we immediately see how both dimensions are related to parent's social background: diagonal lines from the upper left to the lower right for mother's and father's education and profession and for urbanity. Compared with dimension 1, the third dimension is more directly connected with economic capital: it shows a much stronger relation with (self-reported) wealth and SES than the first. In other words, the Western cosmopolitan orientation reflects not only higher parental cultural capital, but also higher parental economic capital. Unsurprisingly, those oriented towards Western culture report better English skills and more travel experience. This dimension is also related to age and gender, with women and younger students more likely to enjoy Asian pop culture. This reflects the statement of some of the interviewees that Korean shows are for teenagers - potentially, it is a phase some of them will grow out of.

In a later phase of this study, we intend to supplement this MCA-based analysis of social background and television taste with more fine-grained statistical analyses, using methods that will also allow us to establish whether these differences are statistically significant. For now, however, we can conclude that the social backgrounds of our informants indeed match the interpretation of the MCA and the interview materials: some television tastes are exclusive, distinctive, and function as Chinese cultural capital.

\section{Conclusion: Popular, cosmopolitan and Bourdieusian distinctions in China?}

Can television taste function as cultural capital in contemporary China? In this paper, we investigated how Chinese students engage with global pop culture to mark their positions in China's swiftly changing social and cultural hierarchies. To the best of our knowledge, this is the first study that explicitly studies cultural capital in China. Many studies have identified the importance of conspicuous consumption and displays of economic capital among Chinese middle classes. However, the consumption of TV is quite unconstrained by economic considerations: all young Chinese can choose quite freely from TV shows from around the world, in a range of genres. Thus, television tastes allow us to gauge whether cultural preferences in themselves are related to social and cultural boundary drawing?

Using a combination of multiple correspondence analysis (MCA) and 48 interviews with students at an elite Beijing university, we identify three distinct taste dimensions: not-knowers versus dislikers; TV lovers versus avoiders; and Western and Eastern TV tastes. We identify dimensions 1 and 3 as cultural capital dimensions. Respondents on the "high end" draw social boundaries vis-à-vis those on the low end, who in turn accept the hierarchies implied in these tastes. The two dimensions differ in the criteria used to make aesthetic distinctions, the type of cultural knowledge they rely on, and in the strength of their boundary-drawing. The "Western" 
taste is more exclusive that the "dislike" taste. The first is mainly based on aesthetic criteria (complexity, authenticity), whereas the second combines aesthetic (complexity, depth) and cosmopolitan (language skills, international experience) distinctions. While the liking of both dimensions is related to parental cultural capital (education, occupation, urbanity), the "Western" taste also correlates with parental economic capital and international experience. These findings also confirm the existence of a "Chain of disdain", where Western television is generally regarded as most prestigious, and Asian, especially Korean commercial culture is ranked lowest.

This "discovery" of cultural capital in China has many implications for the sociology of culture, consumption and stratification, the sociology of globalization and for our understanding of Chinese society in a global context. First, this study brings good news for (post)Bourdieusian cultural sociology because it confirms many well-known mechanisms linking taste to social stratification in a previously unexplored context. In China, too, taste is strongly connected with cultural knowledge. This knowledge is employed to decode and enjoy cultural fare, but also to disparage those who do not have this knowledge. We find stratification within a popular field: "quality" and "lowbrow" popular culture, with their own audidences. The most distinctive tastes are grounded in aesthetic criteria (depth, complexity, realism) and cosmopolitan knowledge, whereas less prestigious taste employ moral (authenticity, warmth, recognizability) or technical (well-made, special effects) evaluations. Moreover, Chinese TV tastes are associated with processes Bourdieu has referred to as "symbolic violence": some informants casually dismiss millions of people on the basis of their preference for local or Korean TV; others willingly embrace cultural hierarchies that harm them. Finally, even in our homogeneous sample, taste is correlated with parental economic and cultural capital.

Second, our study breaks new ground in connecting cultural capital with globalization "from the East". Several researchers have noted the rise of "cosmopolitan capital" as an increasingly important element in processes of cultural distinction (Weenink 2008; Prieur \& Savage 2013; Igarashi \& Saito 2014). For our informants, however, cosmopolitan taste for Western television is the central marker of prestige, above aesthetic criteria. In this respect, Chinese youth may resemble globally oriented urban youth from around the world (Prieur \& Savage 2013). However, there is also something uniquely Chinese about this cosmopolitan taste. The prestige of Western TV has to do with an aspiration towards modernity and a lingering belief in the superiority of (some parts of) Western culture, the status associated with the English language, with international experience (that funnels back to economic capital). It also related to the structure of the television field where the US still set the standards, and the UK is seen as the most innovative (Kuipers 2011). What also makes Chinese cosmopolitanism most uniquely Chinese are its Others: Korean television, and to a lesser extent popular Chinese (Hunan) and Hong Kong TV. The 'chain of disdain' does not only reflect the logics of cultural distinction among Chinese youth, but also the cultural politics of East-Asia, and the changing self-understanding of Chinese in the world.

Thus, this study obviously contributes to our understanding of Chinese society in a global context. It sheds new light on the emergence of the Chinese middle classes, and on the changing patterns of inequality, and particularly: it shows important variations within this emerging middle class. Moreover, it nuances cliché 
images of Chinese consumption as purely materialistic or ostentatious, and of Chinese popular tastes as shaped exclusively by Western import. It is important to remember that although our informants find US and UK shows most prestigious, in the end most of them loved the local shows most.

This study raises a number of important questions for further research, and has some limitations that hopefully can be addressed in further analysis or with follow-up studies. First, our sample is rather small and homogenous. This raises the question whether the patterns we uncovered can be generalized to wider Chinese society: do only young, educated Beijingers care about TV-related cultural capital or is this a wider pattern in Chinese society? Could we find similar pattern for other forms of culture, including traditional highbrow culture such as literature or visual arts? Second, follow-up analysis is needed to analyze the cultural logics and criteria underlying Chinese TV taste patterns. More particularly, we need to look at the "silent majority". The people who do not score highly on the dimensions have received relatively scant attention, whereas they of course make up the majority of our informants.

A further analysis of the interviews might also answer a final important question: whereas we have found evidence for cultural capital in China, have we found Bourdieusian cultural capital? In the original formulation, cultural capital negates economic capital (Bourdieu 1984). This negation of economy can also be found in European and US studies of popular cultural capital: avant-garde pop culture is the domain of the poor. Even in the money-driven television field, this opposition between culture and economy is visible. (Kuipers 2011) Our findings, so far, show little evidence of a Chinese belief in the incompatibility of cultural worth and economic profit (see also Kharchenkova \& Velthuis 2018). While this may be the result of our focus on television, it seems plausible that this particular trait of the Euro-American cultural field does not travel well. 


\section{References}

Adorno, T. W., \& Horkheimer, M. (1979 [1944]). The culture industry: Enlightenment as mass deception. In J.

Curran, M. Gurevitch, \& J. Woollacott (Eds.), Mass communication and society (pp. 349-383). Thousand Oaks: Sage.

Anagnost, A. 2008. From "Class" to "Social Strata": Grasping the social totality in reform-era China. Third World Quarterly, 29 (3), 497-519.

Ang, I. (1985). Watching Dallas: Soap opera and the melodramatic imagination. London: Routledge.

Bachmayer, T., Wilterdink, N., \& van Venrooij, A. (2014). Taste differentiation and hierarchization within popular culture: The case of salsa music. Poetics, 47, 60-82.

Baumann, S. (2007). Hollywood highbrow: From entertainment to art. Princeton: Princeton University Press.

Bennett, T., Savage, M., Silva, E. B., Warde, A., Gayo-Cal, M., \& Wright, D. (2009). Culture, class, distinction. London: Routledge.

Benzécri, J. (1973). L'analyse des données (Vol. 2). Paris: Dunod.

Bian, Y. (2002). Chinese social stratification and social mobility. Annual Review of Sociology, 28, 91-116.

Bianculli, D. (2016). The platinum age of television: from I Love Luy to The Walking Dead, how TV became terrific. New York: Doubleday.

Bourdieu, P. (1984). Distinction: A social critique of the judgement of taste. London: Routledge.

Bourdieu, P. (1986). The forms of capital. In J. Richardson (Ed.) Handbook of Theory and Research for the Sociology of Education (pp. 241-259). New York: Greenwood.

Bryson, B. (1996). Anything but heavy metal: symbolic exclusion and musical dislikes. American Sociological Review, 61, 884-899.

Calhoun, C. (2002). The class consciousness of frequent travelers: Toward a critique of actually existing cosmopolitanism. South Atlantic Quarterly, 101(4), 869-897. 
China Daily. (2015). Ten favorite British TV shows among Chinese audiences. Retrieved from http://www.chinadaily.com.cn/interface/yidian/1139302/2015-10-20/cd_22232179.html

Chua, B., and Iwabuchi, K. (eds.). (2008). East Asian pop culture: Analysing the Korean wave. Vol. 1. Hong Kong: Hong Kong University Press.

Cui, B. (2010). Comment: Japanese TV Drama in China. Symposium: International Exchange in TV Drama Productions. JAMCO Online International Symposium. http://www.jamco.or.jp/en/symposium/19/6/

Davis, D. (Ed.). (2000). The consumer revolution in urban China (Vol. 22). Berkeley: University of California Press.

Fewsmith, J. (2007). The political implications of China's growing middle class. China Leadership Monitor, 21, 1 8.

Friedman, S. (2011). The cultural currency of a 'good' sense of humour: British comedy and new forms of distinction. The British Journal of Sociology, 62(2), 347-370.

Friedman, S. (2016). Habitus clivé and the emotional imprint of social mobility. The Sociological Review 64(1), 129-147.

Friedman, S., \& Kuipers, G. (2013). The divisive power of humour: Comedy, taste and symbolic boundaries. Cultural Sociology, 7(2), 179-195.

Friedman, S., Savage, M., Hanquinet, L., \& Miles, A. (2015). Cultural sociology and new forms of distinction. Poetics, 53, 1-8.

Fong, V. (2011). Paradise redefined: Transnational Chinese students and the quest for flexible citizenship in the developed world. Stanford University Press.

Gans, H. (1974). Popular culture and high culture: An analysis and evaluation of taste. Basic Books.

Gao, Y. (2016). Fiction as reality: Chinese youths watching American television. Poetics, 54, 1-13. 
Greenacre, M. J., \& Blasius, J. (1994). Correspondence analysis in the social sciences: Recent developments and applications. London: Academic Press.

Hedegard, D. (2015). Transnational connections: The meaning of global culture in the tastes of Brazilian elites. Poetics, 53, 52-64.

Holt, D. (1997). Distinction in America? Recovering Bourdieu's theory of tastes from its critics. Poetics, 25(2), 93-120.

Igarashi, H. \& Saito, H. (2014). Cosmopolitanism as cultural capital: Exploring the intersection of globalization, education and stratification. Cultural Sociology, 8(3), 222-239.

Iwabuchi, K. (2002). Recentering globalization: Popular culture and Japanese transnationalism. Durham: Duke University Press.

Jarness, V. (2015). Modes of consumption: From 'what' to 'how' in cultural stratification research. Poetics, 53, 65-79.

Kharchenkova, S., \& Velthuis, O. (2017). How to become a judgment device: valuation practices and the role of auctions in the emerging Chinese art market. Socio-Economic Review 16(3): 459-477.

Kuipers, G. (2006). Television and taste hierarchy: The case of Dutch television comedy. Media, Culture \& Society, 28(3), 359-378.

Kuipers, G. (2011). Cultural globalization as the emergence of a transnational cultural field: Transnational television and national media landscapes in four European countries. American Behavioral Scientist 55(5), 541-557.

Kuipers, G. (2015). Good humor, bad taste: A sociology of the joke. Berlin: De Gruyter.

Lamont, M. (1992). Money, morals, and manners: The culture of the French and the American upper-middle class. Chicago: University of Chicago Press.

Lamont, M., \& Fournier, M. (Eds.) (1992). Cultivating differences. Chicago: University of Chicago Press. 
Lamont, M., \& Molnár, V. (2002). The study of boundaries in the social sciences. Annual Review of Sociology, 28, 167-195.

Li, Cheng. 2010. China's Emerging Middle Class: Beyond Economic Transformation. Washington: Brookings Institution Press.

Liebes, T., \& Katz, E. (1990). The export of meaning: Cross-cultural readings of Dallas. New York: Oxford University Press.

Lizardo, O., \& Skiles, S. (2009). Highbrow omnivorousness on the small screen?: Cultural industry systems and patterns of cultural choice in Europe. Poetics 37(1), 1-23.

Lotz, A. D. (2014). The television will be revolutionized. New York: NYU Press.

Lull, J. (1991). China turned on: Television, reform, and resistance. London: Routledge.

Martin, B. (2013). Difficult men: Behind the scenes of a creative revolution. London: Penguin.

McCabe, J., \& Akass, K. (2007). Quality TV: Contemporary American television and beyond. London: IB Tauris.

McCoy, C. A., \& Scarborough, R. C. (2014). Watching "bad" television: Ironic consumption, camp, and guilty pleasures. Poetics, 47, 41-59.

Mittell, J. (2015). Complex TV: The poetics of contemporary television storytelling. New York: NYU Press.

Nenadic, O., \& Greenacre, M. (2007). Correspondence analysis in R, with two-and three-dimensional graphics: The ca package. Journal of statistical software, 20(3). DOI: 10.18637/jss.v020.i03

Olsson, J., \& Spigel, L. (Eds.). (2004). Television after TV: Essays on a Medium in Transition. Duke University Press.

Osburg, J. (2013). Anxious wealth: Money and morality among China's new rich. Stanford: Stanford University Press.

Peterson, R. A., \& Kern, R. (1996). Changing 'highbrow' taste: From snob to omnivore. American Sociological Review, 61(5), 900-907. 
Peterson, R. 2005. "Problems in Comparative Research: The Example of Omnivorousness." Poetics 33: 257282.

Postman, N. (1985). Amusing ourselves to death: Public discourse in the age of television. New York, NY: Viking.

Prieur, A., \& Savage, M. (2013). Emerging forms of cultural capital. European Societies, 15(2), 246-267.

Ryoo, W. (2009). Globalization, or the logic of cultural hybridization: The case of the Korean wave. Asian Journal of Communication 19(2), 137-151.

Sora, P. (2004). China's consumption of Korean television dramas: An empirical test of the "Cultural Discount" concept. Korea Journal, 44, 265-290.

Straubhaar, J. D. (2007). World television: From global to local. Thousand Oaks: Sage.

Warde, A., Silva, E., Bennett, T., Savage, M., Gayo-Cal, M., \& Wright, D. (2009). Culture, class, distinction. London: Routledge.

Weenink, D. (2008). Cosmopolitanism as a form of capital: Parents preparing their children for a globalizing world. Sociology, 42(6), 1089-1106.

Xu, H. J. (2009). Building a Chinese 'middle class': Consumer education and identity construction in television land. In Y. Zhu, \& C. Berry (Eds.), TV China (pp. 150-167). Bloomington: Indiana University Press.

Yan, Y. (2013). Of hamburger and social space: Consuming McDonald's in Beijing. In C. Counihan \& P. van Esterik (eds), Food and culture: A reader (449-471). New York: Routledge.

Zhu, Y., \& Berry, C. (Eds.) (2009). TV China. Bloomington: Indiana University Press. 